\title{
La transformación barroca del interior de la cate- dral de León. Una idea con una larga gestación
}

\author{
Emilio Morais Vallejo
}

Universidad de León

RESUMEN. El presente trabajo trata sobre la profunda transformación que sufrió durante el barroco el espacio interior de la catedral de León, aportando nueva documentación, datos inéditos y recopilando las principales noticias que se conocían hasta ahora de manera dispersa y no sistematizada. Con esta información se pretende esclarecer la idea que se fue gestando sobre la fisonomía que debía presentar una catedral barroca para satisfacer los intereses de la ideología religiosa dominante en aquel momento histórico, así como los artífices que la hicieron posible.

Palabras clave: Barroco, arquitectura, catedral, restauración, León.

ABSTRACT. This work offers an analysis of the profound tranformation that took place in the interior of the León cathedral during the Baroque era. To this end it makes use of recent investigation, previously unpublished data and the compiling of information that until now had only been available from disperse, disorganized sources. This information attempts to clarify the idea that evolved regarding the ideal appearance of a Baroque cathedral, a cathedral designed to suit the interests of the dominant religious ideology of the times as well as that of those who made its construction possible..

Key words: Baroque, architecture, cathedral, restoration, León.

Es frecuente ver como se compara a las catedrales con organismos vivos. La razón de tal símil se debe a que son edificios que están en constante renovación porque necesitan mantenerse en las mejores condiciones posibles para cumplir con efectividad su alta misión como iglesia mayor de su diócesis, además de ser una representación elocuente del poder episcopal. Por otro lado, al estar constituidas por un conjunto de espacios de distinta configuración, que tienen diferentes valores, presentan una variedad de registros que nunca pueden considerarse concluidos. En consecuencia, obispos y cabildos de todas las épocas han destinado grandes cantidades de dinero y energías con el fin de conseguir que sus sedes estuvieran en disposición de alcanzar los objetivos que, en cada momento y situación, demandaba la ideología eclesiástica para adaptarse a la evolución de la sociedad. En otras ocasiones fue al contrario, el cambio buscaba precisamente orientar la evolución de la sociedad en un determinado sentido.

Los factores que contribuyen en esa permanente evolución de los templos catedrali- cios son de muy diversa índole. En primer lugar hay que tener en cuenta el deterioro inexorable del paso de los años, pero ni es el único ni el más decisivo para motivar una actuación arquitectónica o artística en los edificios. También son importantes las modificaciones que va sufriendo la liturgia, la evolución del gusto de la sociedad, las novedades arquitectónicas, e incluso otras cuestiones más subjetivas como pueden ser los cambiantes intereses de obispos y cabil$\operatorname{dos}^{1}$. Al mismo tiempo no debemos olvidar que la catedral es la iglesia madre de la diócesis que regenta, y se convierte en espejo y baluarte para el resto de los templos que controla, tanto en su vertiente eclesiástica como en la artística. Así, las actuaciones arquitectónicas realizadas en ellas, muchas veces ejerciendo de vanguardia en las innovaciones técnicas o en los cambios estilísticos, marcan las tendencias estéticas de cada época, a las que se van adaptando los edificios

-

${ }^{1}$ La cuestión se plantea desde distintas vertientes en AA. VV., Las catedrales españolas en la Edad Moderna, Madrid, 2001. 
del territorio que dirigen ${ }^{2}$. La cuestión resulta más evidente en las zonas consideradas periféricas, como era el caso de León durante la Edad Moderna, donde las novedades tardaban más en llegar y se transmitían con grandes dificultades ${ }^{3}$.

La atención constante de las catedrales se traduce en sucesivas intervenciones, consideradas siempre como necesarias por sus gerentes, actuando tanto sobre la piel como sobre la estructura de las fábricas. Las actuaciones, realizadas para adaptarse a las nuevas necesidades surgidas con el tiempo, son de varios tipos, que van desde la restauración de las partes deterioradas, la sustitución de las más las anticuadas o la simple renovación del aparato exornativo, hasta la reconstrucción total de elementos emblemáticos, aunque otras veces también se hacen algunos añadidos para satisfacer necesidades sobrevenidas, e incluso en ocasiones se decide la conclusión del edificio que ha llegado incompleto. De todo ello se infiere una alteración significativa de la fisonomía primitiva, marcada por la suma de las diferentes operaciones, unas veces armónicas con los vestigios del pasado y otras contradictorias. Al final, los edificios catedralicios, deudores de su historia, quedan marcados con la impronta personal de cada etapa, lo cual les otorga una mayor personalidad e individualiza aquellos que se iniciaron en su misma época y estilo.

El periodo barroco, como no podía ser de otra manera, fue prolífico en cuanto a intervenciones en las catedrales españolas, muchas de las cuales fueron motivadas por las novedades estéticas surgidas en la sociedad de la época, mientras que otras fueron hechas para llevar a la práctica los principios teóricos del concilio de Trento, exigiendo ambas la realización de cambios sustanciales en los templos heredados del pasado ${ }^{4}$. Algunas de estas modificaciones se han

\section{-}

${ }^{2}$ El papel de promoción de la catedral lo analiza J. J. MARTÍN GONZÁLEZ, "La catedral como núcleo promotor del barroco español", en I Congresso Internacional do Barroco, vol. II, Porto, 1991, pp. 4-16.

${ }^{3}$ El tema se estudia en un ejemplo similar al de León en M. A. GONZÁLEZ GarCía, "La diócesis como centro periférico de influencia artística: el caso de Astorga en los siglos XVI y XVII (Las periferias de la periferia)", Actas VIII Congreso Nacional de Historia del Arte, Mérida, 1992, pp. 243-247.

${ }^{4}$ La influencia del concilio de Trento en la arquitectura de la época la analiza A. RodRíguez G. DE CEBALlos, "Liturgia y configuración del espacio en la arquitectura española y portuguesa a raíz del Concilio de Trento", Аnиa- mantenido hasta la actualidad, otras han sido substituidas o alteradas, pero de cualquier manera tenemos que reconocer que la marca peculiar de la época del barroco modificó sustancialmente el carácter que tenían hasta entonces los primeros edificios de las diócesis ${ }^{5}$. Como dice la profesora Tovar Martín, la idea de catedral barroca se inserta en la catedral antigua para transformarla, utilizando un nuevo sistema de valores, ejecutando una arquitectura distinta, naturalmente vinculada a su contexto artístico y cultural $^{6}$. Los viejos edificios son magníficas obras de arte que nadie se plantea demoler para sustituir por otros, como por otra parte hicieron con bastante facilidad otras épocas; cosa que no hizo el barroco ni por razones económicas ni por razones estéticas. La intención era extraer la máxima rentabilidad ideológica, estética y funcional de los viejos templos para ser utilizada en los nuevos tiempos con significación distinta, para lo cual era necesaria la transformación ${ }^{7}$. No obstante, hemos de destacar que las intervenciones casi siempre fueron planteadas desde un enorme respeto a los valores del edificio heredado y con clara conciencia de que se quería su conservación en un mejor estado, o en todo caso, una rehabilitación para su correcto funcionamiento ${ }^{8}$. A la hora de intervenir, unas veces se emplearon formas novedosas, pero acopladas al entorno, otras veces se hicieron actuaciones pretendidamente miméticas para no desentonar con el conjunto transmitido por la historia, pero siempre parece existir el sentimiento de que se actuaba sobre un edificio antiguo que exige el máximo respeto por el alto valor intrínseco de su legado. La mayoría de estas cuestiones las vamos a ver referidas al caso del primer edificio eclesiástico de León.

rio del Departamento de Historia y Teoría del Arte, vol. III, Madrid, 1991, pp. 43-53.

${ }^{5}$ El barroco fue una época de gran actividad artística y arquitectónica en las catedrales españolas. Algunas de las actuaciones más importantes se tratan en sendos volúmenes recientes que ofrecen un panorama general sobre el tema, AA VV, Las catedrales españolas. Del barroco a los historicismos, G. RAMALlo ASENSIO (ed.), Murcia, 2003; M. P. DíAZ MuÑOZ, Catedrales en el barroco, Madrid, 2003.

${ }^{6}$ V. Tovar Martín, El Arte del Barroco. Arquitectura, Madrid, 1990, p. 115.

${ }^{7}$ A. ROSENDE VALDÉS, "La modificación de las tipologías tradicionales en el mundo moderno: la ampliación y reforma de las catedrales gallegas" en Las catedrales españolas en la Edad Moderna, Madrid, 2001, p. 52.

${ }^{8}$ V. Tovar Martín, Los siglos del barroco. Arquitectura, Madrid, 1997, p. 60. 
La historia constructiva de la actual catedral leonesa es larga y compleja ${ }^{9}$. Se empezó a levantar en el siglo XIII en el solar que ocupara la antigua románica, y a lo largo del gótico fue tomando las sucesivas formas particulares de las fases que caracterizan dicho período, hasta dejarla casi terminada. La esperada conclusión, aunque fuera provisional como ya explicábamos antes, se produjo durante el siglo del renacimiento, momento en el que también se hicieron interesantes añadidos y reformas necesarias para solucionar los problemas estructurales que desde muy pronto habían surgido en la fábrica. A partir de ese momento hubo dos grandes transformaciones que cambiaron en gran medida la esencia gótica del primitivo edificio leonés. Una se produjo durante el barroco, como analizamos a continuación, cuando se realizó una amplia modificación que afectó sobre todo a la concepción del espacio interior. Sin embargo, más tarde triunfó la idea de borrar de la catedral todos los vestigios posibles del barroco, considerado como un estilo decadente y sin elegancia. Actuaron en este sentido primero los académicos y el gusto del neoclasicismo, después los ideales románticos, y por fin las corrientes historicistas, con su pretensión de dejar al edificio en su forma prístina. Precisamente ésta es la segunda gran transformación de la catedral leonesa, llevada a cabo en la profunda restauración decimonónica por arquitectos como Laviña, Madrazo, Demetrio de los Ríos o Torbado, entre otros, que la convirtieron en un modelo gótico con pretensiones de purismo. Siguiendo las teorías restauradoras herederas de Viollet le Duc, aniquilaron sin ninguna reserva la mayor parte de las huellas que la historia había dejado sobre ella ${ }^{10}$. Por esta razón hoy en día no quedan muchos restos de la intervención barroca que vamos a tratar, la cual podemos conocer, muy fragmentariamente, gracias sobre todo a la documentación conservada y a los dibujos realizados en su momento, no tanto por su existencia material.

${ }^{9}$ Para conocer la historia constructiva de la catedral leonesa véase M. VALDÉS Y OTROS, Una historia arquitectónica de la Catedral de León, León, 1994.

${ }^{10}$ Sobre las restauraciones de la catedral leonesa véase, J. Rivera BlanCO, Historia de las restauraciones de la catedral de León, Valladolid, 1993; I. GoNZÁLEZ-VARAS, La catedral de León. Historia y restauración (1859-1901), León, 1993; también el catálogo de la exposición La Catedral de León. El sueño de la razón, León, 2001.
A lo largo de los siglos del barroco la catedral gótica de León sufrió una serie de actuaciones que terminaron por cambiar la fisonomía del templo, pasando de tener una genuina apariencia medieval a conseguir otra insólita, más acorde con la necesidad, la estética y el gusto propios de la época moderna. Las actuaciones fueron dirigidas especialmente a cambiar por dentro el templo, hasta hacer una verdadera metamorfosis del edificio ${ }^{11}$. A diferencia de otras catedrales españolas, preocupadas por terminar el edificio, hacer una nueva fachada, añadir estancias o culminar torres, León presenta la novedosa idea de modificar el espacio interior del templo por medio de actuaciones de todo tipo. Había un deseo de reflejar el cambio de época, para lo cual era necesario no sólo hacer nuevas estructuras arquitectónicas, sino también modificar de forma sustancial el carácter exornativo heredado del gótico. En su intención primaba, sin duda, la adición de nuevos elementos que ayudaran a actuar sobre el ánimo de los fieles, con el fin de conseguir el efecto persuasivo que caracteriza al arte del barroco. Todo lo cual es independiente de las construcciones necesarias para solucionar los problemas estructurales que llevaron, ya en esta época, a la ruina de ciertas partes de la catedral ${ }^{12}$. Por otro lado, llama la atención el hecho de que el exterior apenas fue modificado, salvo el lógico reflejo de las obras interiores. Sólo cuando la estabilidad del edificio hizo necesaria la restauración del hastial meridional se aplicaron las formas del nuevo léxico a esta parte, aunque sin que fueran excesivamente rompedoras con la tradición ${ }^{13}$. Lo mismo podemos decir del remate

${ }^{11}$ El término metamorfosis lo utilizamos con el significado dado por A. CAPITEL, Metamorfosis de monumentos y teorías de restauración, Madrid, 1988, p. 11, pues una configuración inédita dio respuesta a las carencias de lo antiguo según las nuevas necesidades, pero respetando los valores del edificio legado.

${ }^{12}$ Los mayores problemas se localizaban en el crucero y zonas aledañas, como la llamada Silla de la Reina, intervenida en aquella época, o las capillas de El Carmen y de la Virgen del Dado, que se arruinaron y tuvieron que rehacerse durante el barroco. Cfr. J. Rivera BlanCO, Historia de las restauraciones..., p. 111-140; E. MORAIS VALLEJO, Aportación al barroco en la provincia de León. Arquitectura religiosa, León, 2000, pp 309-310.

${ }^{13}$ El cabildo catedralicio encargó a Manuel Conde Martínez hacia 1694 que hiciera un proyecto de restauración para sustituir el remate del hastial meridional, que fue ejecutado más tarde. Véase, P. NAVASCuÉs PALACIO, "La arquitectura del siglo XIX: las fachadas de la catedral de León", Estudios Pro-Arte, n ${ }^{\circ}$ 9, 1977, p. 54; J. RIVERA BLANCO, Historia de las restauraciones..., p. 118-129; E. 
de la torre norte, rehecho por Joaquín de Churriguera tras la caída de un rayo, que pasa desapercibido en una visión de conjunto ${ }^{14}$, al igual que sucede con otros elementos como pináculos, arbotantes o contrafuertes, restaurados para solucionar problemas físicos o mecánicos. Parece claro que la preocupación primordial estaba en el interior, ya que la cuestión era más ideológica que estética, más relacionada con los significados que tienen las formas que con la mera apariencia. En cualquier caso, destacamos la gran actividad del momento, lo que demuestra que no sólo se quería dejar impronta de una época o de un estilo, sino también hacer un cambio en profundidad.

El protagonista de la reforma fue sin duda el cabildo catedralicio, ya que los obispos que dirigieron la sede leonesa durante la Edad Moderna, salvo raras excepciones, no tuvieron entre sus preocupaciones la comprobación del estado del edificio o el inicio de las renovaciones, siendo la mesa capitular responsable y promotora de la práctica totalidad de las actuaciones que se hicieron durante aquellos siglos en la fábrica ${ }^{15}$. Lamentablemente el estilo lacónico de las actas capitulares y la pérdida de muchos documentos, nos han dejado con pocos datos para conocer en toda su amplitud y complejidad las discusiones y los argumentos esgrimidos para la transformación. Por lo tanto, hemos de deducirlos de las escasas referencias conocidas $\mathrm{y}$ de los hechos que ejemplifican ideas incuestionables.

La metamorfosis se inició con el pretexto de solucionar los problemas arquitectónicos que tenía el edificio, para después ir poco a poco introduciendo el resto de las novedades. El cabildo decidió corregir los graves desperfectos que sufría la catedral, y aprovechó la ocasión para conseguir la transformación del edificio gótico con obras que comprendían añadidos, restauraciones, reconstrucciones y reformas estructurales, a las que hay que sumar la inclusión de nuevo mobiliario eclesiástico. El proce-

MORAIS VALLEJO, Aportación al barroco..., pp 307-309; M. D. CAMPOS SÁNCHEZ-BORDONA, "Las transformaciones del Renacimiento y el esplendor barroco", en Una historia arquitectónica de la Catedral de León, León, 1994, pp 210214.

${ }^{14}$ E. MoRais VAllejo, Aportación al barroco..., p. 309.

${ }^{15}$ M. D. CAMPOS SÁNCHEZ-BORDONA, "Las transformaciones ..., p. 136. so fue lento, pues se inició a finales del primer tercio del siglo XVII y no se concluyó hasta mediados de la centuria siguiente, en una cronología que coincide con la tradicionalmente atribuida al barroco. No hubo en principio una programación estructurada ni única; al contrario, se sucedieron distintas obras que se fueron superponiendo en el tiempo sin una línea maestra clara, pero que si las unimos resulta evidente que tenían un mismo hilo argumental: suplir las carencias y modernizar la apariencia según la idea barroca de lo que debía ser una catedral moderna, adecuando sus espacios a las necesidades litúrgicas, ideológicas y estéticas de la época. Para conseguirlo era necesario que hubiera una decidida aceptación de las corrientes artísticas predominantes en la época y una falta de interés por mantener la unidad de estilo en el edificio heredado. Este deseo de innovación trajo como consecuencia la inserción en el templo de obras arquitectónicas, pictóricas y escultóricas novedosas, unidas en un mismo fin, aunque realizadas en un largo lapso de tiempo.

Vamos a hablar sobre algunas cosas que hoy en día no existen, se han modificado o han cambiado de lugar o significación. Recomponer la catedral que alguna vez existió es muy difícil, y nunca podremos saber con exactitud como fue en realidad la catedral barroca de León ${ }^{16}$. Contamos con fotos y dibujos antiguos que nos ayudarán en nuestro viaje hacia el pasado; en otros casos disponemos de algunos restos de aquella realidad, pero con frecuencia tendremos que invocar a la imaginación para "ver" como fue aquella catedral, desmantelada posteriormente.

La transformación giró alrededor de tres obras fundamentales, que indujeron a su vez otras actuaciones complementarias que fueron determinantes en el resultado final. Primero se decidió levantar una gran cúpula sobre el crucero, lo cual no sólo alteraba de forma evidente la fisonomía del edificio sino que también intervenía de forma peligrosa en la estabilidad de la complicada estructura arquitectónica del gótico, siendo determinante para la futura integridad de la catedral. Más tarde se encargó un gran retablo para culminar la capilla mayor con el esplendor

-

${ }^{16}$ El mismo lamento sobre la pérdida irremediable de una parte de la historia lo hace G. RAMALlo ASENSIO, "Aspectos generales de las catedrales españolas en el barroco y su proyección al siglo XIX", en Las catedrales españolas. Del barroco a los historicismos, Murcia, 2003, p. 13. 
propio del barroco, lo cual motivó a su vez, como tercera obra importante, la necesidad de trasladar el coro desde su ubicación primitiva en el presbiterio hasta la nave mayor, con la modificación radical del espacio que esto suponía. Al tiempo fue necesario redefinir los límites del presbiterio con la colocación de rejas, prolongar los cierres laterales del coro, encargar un nuevo órgano, marcar la vía sacra, enlosar la capilla mayor y hacer nuevos púlpitos, entre otras obras menores. Al final resultó que la modificación espacial, hecha para conseguir un nuevo significado de intencionalidad barroca, circulaba alrededor de la zona del templo donde el cabildo tenía todo el protagonismo -coro, vía sacra y capilla mayor-, aquella en la que los fieles no podían entrar y se convertían en meros espectadores a distancia de los ritos que allí se celebraban.

El cabildo consideraba que estos trabajos eran muy delicados para dejarlos en manos inexpertas. La consciencia de estar interviniendo sobre un edificio histórico de singular valor obligaba a la máxima prudencia, por eso era preciso la concurrencia de los más prestigiosos maestros de cada momento y los especialistas en cada trabajo, aquellos que pudieran garantizar un resultado de calidad. También se procuró contratar a los que ya habían demostrado su pericia en edificios importantes y demostraban conocer el funcionamiento de las grandes máquinas arquitectónicas medievales; pero también, y sobre todo, a los que representaban los nuevos valores de la estética barroca. No obstante, para evitar errores, además de la esmerada elección de los directores de las obras, la precaución se completaba con la petición de informes externos sobre las obras proyectadas o en curso.

Los maestros locales no fueron considerados suficientemente cualificados, siendo destinados a ejercer funciones en puestos secundarios; situados en un escalón inferior se mantuvieron a las órdenes de los presentados con la vitola de superioridad. Así empezaron a llegar a León artífices de prestigio, unos para hacer las trazas de las nuevas obras, otros para ejercer de hecho la dirección de los trabajos, y los demás para emitir juicios de carácter arquitectónico y técnico. En cualquier caso, todos aportaron su ingenio, además de su trabajo, para la feliz consecución de los deseos del cabildo. Entre los llegados había algunos avalados por los cargos oficiales que ostentaban en prestigiosas institu- ciones civiles, pero sobre todo vinieron maestros mayores procedentes de las catedrales del entorno. Un aspecto destacable es la relación entre distintos cabildos catedralicios, pues en ocasiones mantenían contactos para solicitar arquitectos, aparejadores u oficiales, que eran cedidos entre ellos de forma generosa. Un ejemplo lo tenemos en mayo de 1743 cuando el cabildo leonés, con motivo de la ruina de la capilla del Carmen, decidió solicitar un oficial cualificado a la catedral de Salamanca para realizar esta obra ${ }^{17}$. Fue elegido Alonso de la Fuente Rodríguez, quien en aquellos momentos era maestro de obras en las casas del cabildo de aquella diócesis ${ }^{18}$. Terminados los trabajos fue rescindido su contrato y se decidió escribir al cabildo de Salamanca para dar las gracias por la cesión y notificar el salario pagado por la labor realizada, lo que demuestra que hasta la retribución era consensuada entre las citadas instituciones eclesiásticas ${ }^{19}$.

Lo mismo sucedía con los maestros mayores de las catedrales, sirviendo como muestra el caso de Pantaleón del Pontón Setién, quien obtuvo permiso para actuar en el primer templo leonés cuando estaba a las ordenes del cabildo salmantino dirigiendo su fábrica ${ }^{20}$. El paralelo con un cargo civil lo tenemos en el italiano Giacomo Pavía, quien llegó a León en marzo

\section{-}

${ }^{17}$ Archivo de la Catedral de León (desde aquí A.C.L.), Fondo General, doc. 10.036, s/f:

...que el Sr. Santos escriba al Sr. Penitenziario de Salamanca encargando a su cuidado la agenzia de un ofizial diestro en aparejar, asentar, dar el corte a las piedras, segun las plantillas y trazas del maestro, y para que cuide de los demas ofiziales, y sus tareas; y para que trabaje en lo demas que en esta yglesia se ofreciere....

18 A.C.L., Fondo General, doc. 10.036, s/f.:

...echo cargo el cabildo de las circunstancias y abilidad que concurren en A. F. $R$ maestro de obras en las casas del cabildo de Salamanca; que son las mismas que se necesitan para el decurso de las obras de Nuestra Yglesia

19 A.C.L., Fondo General, doc. 10.036, s/f.:

...se le escriba a la Santa Yglesia de Salamanca las gracias y como este sujeto a cumplido exactamente y que al $\mathrm{Sr}$. Penitenciario se le escriba lo que al maestro se le a dado... y que si no es bastante le de dicho señor lo que le pareziere, y luego que abise, se le libre.

${ }^{20}$ A.C.L. Fondo General, doc. no 11.039, s./f.:

...don Pantaleon del Ponton Septien, criado de V $S^{a} \mathrm{Il}$ ma., puesto a sus pies, dize como el año pasado de 710 por el mes de abril, favorezido de V. $S^{a}$ vino a esta ciudad con lizenzia que tubo del cavildo de Salamanca para ber la obra que se pretendia hazer sobre la nedia naranja, y haviendolo reconozido y considerado en todas sus zircunstanzias, hallo se podia ejecutar con toda firmeza y seguridad, segun la ydea y modo que entonzes conzibio. 
del año $1745^{21}$, estando en aquellos momentos ligado a la Real Academia de Arquitectura de la Corte asentada en Madrid. El cabildo de León, interesado en contratar sus servicios para solucionar las deficiencias de la fábrica catedralicia, tuvo que solicitar permiso para que se quedara en la ciudad cuando demostró su eficiencia y disposición para trabajar en distintos campos de la construcción. La petición se cursó en abril de 1745 dirigida a Baltasar de Elgueta y Vigil, que era en aquellos momentos Intendente de la obra del palacio real $^{22}$, siendo concedida la licencia real en seguida, como muestra de la buena relación entre la monarquía y la catedral leonesa ${ }^{23}$

${ }^{21}$ A.C.L., Fondo General, no ${ }^{\circ} 9.678$, fol. 190, Libro de asiento de las libranzas que va dando el canónigo Diego de Escobar, administrador de la fábrica de la catedral, con motivo de diversas obras en la catedral:

....Maestro don Jacobo de Pavia entro en esta ciudad el dia primero de marzo de 1745.

${ }^{22}$ A.C.L., Fondo General, doc. 8.778, fol. 83:

Quando don Santiago Pavia, Director de la Real Academia de Architectura en esa Corte vino aqui a reconocer la obra que va hecha en este templo y dar su parecer y direccion sobre la que faltaba, discurriamos que podia despachar mui luego y restituirse inmediatamente a su destino; pero viendo nosotros que la especial habilidad de este sugeto nos proporciona y facilita el perfeccionar en breve tiempo lo que veiamos en la experiencia de bastante duracion, y temiendo por otra parte que la falta de su persona pueda hacer variar en la practica sus nobles y acertadas ideas, y quedar expuesta a este y otros considerables daños esta antigua y celebrada santa yglesia, dirigimos a V. S. con la mas profunda confianza nuestras suplicas, para que se sirva alcanzarnos de la piedad del Rey N. S., Dios le guarde, el permiso de que se detenga aqui el dicho don Santiago unos meses, que se reputan por suficientes para la conclusion del trabajo, esperando que la real clemencia de su Magestad renueve en esta gracia las singulares, que dispensa en beneficio y reparo de esta fabrica, y que V. S. contribuya con su influjo a motivo tan piadoso, imponiendonos con su importante mediacion y oficios la mas estrecha obligacion, a cuyo cumplimiento resignamos desde aora nuestra fiel obediencia, deseosos de emplearla en obsequio de V. S. y sus preceptos

${ }^{23}$ A.C.L., Fondo General, doc. 8.778, fol 86:

Don Balthasar de Elgueta y Vigil, Intendente de la obra del real palacio

Avisa haver conseguido licencia de su magestad para que don Santiago Pavia se detenga algun tiempo para la conclusion de la obra de esta santa yglesia.

Haviendome con el maior gusto afecto y boluntad de servir a V. I., dedicado a la solicitud de que don Santiago Pavia subsista los meses que se reputan suficientes para la conclusion de la obra que resta en esa santa yglesia; a fin de no abenturar con la falta de su persona la practica de sus ideas, pasando los oficios correspondientes con el señor marqués de Villarias, ha venido $S$. M. en que don Santiago se detenga por algun tiempo mas, con que quedando V. S. I. servido en este asumpto, a correspondencia de mis deseos de complacerles espero me dispense todos los demas de su maior satisfaczion y agrado, para exercitar mi resignada
Se produjo de esta forma un sugestivo trasvase de artífices que se convirtió en un flujo de ideas que se hicieron compartidas en muchos lugares a la vez, prueba de ello es, por ejemplo, la clara influencia formal que es posible encontrar entre las distintas catedrales de Castilla y León. Al mismo tiempo, esto demuestra que la empresa de hacer en León una catedral barroca a partir de la gótica no era una cuestión aislada, ni tan siquiera particular del cabildo, sino que era una idea compartida por los más prestigiosos arquitectos del momento, interesados en dejar la impronta barroca en los principales templos del reino.

\section{LAS OBRAS DE TRANSFORMACIÓN Y SUS ARTÍFICES.}

La catedral ya presentaba una situación de deterioro preocupante a finales del siglo XVI, según se deduce de un dictamen de 1584 en el que se advierte de la ruina de algunas partes del edificio ${ }^{24}$, así como de los trabajos restauradores llevados a cabo por Baltasar Gutiérrez, quien estuvo al frente de la fábrica hasta su muerte en $1604^{25}$. Los problemas estructurales y de conservación no fueron resueltos entonces, como queda de manifiesto en el informe realizado en 1637 por Juan de Naveda a petición del cabildo, en el que hace un relato exhaustivo de los males de la fábrica y da cuenta del lamentable estado de muchos elementos arquitectónicos que necesitaban una urgente intervención para evitar su ruina inminente ${ }^{26}$.

obediencia, en obsequio de V. S. I. que guarde nuestro señor los mas años que le suplico.

${ }^{24}$ A.C.L., Fondo General, doc. 8.786, s/f.

${ }^{25}$ D. DE Los Ríos, La catedral de León. Monografia, t. II, Madrid, 1895, pp. 19 y 20

${ }^{26}$ A.C.L., Fondo General, doc. 11.004, s/f.

...Y porque a mi como yndigno maestro de las obras que V. $S^{a}$ en la ylustre e ynsigne obra de su Sancta Yglesia me toca el dar quenta a V. $S^{a}$ de los daños que en ella pueden suçeder y ban resultando con las nieves y aguas que de continuo la persiguen por la cubierta de sus tejados y los que la salida de las dichas aguas por sus conductos causan en los estribos pilares y arbotantes que fortifican manotienen ermosean y estrivan la fuerça del peso de sus capillas y ansi mismo el que haçen los grandes ayres y aguas que con su furioso ynpetu son arrojadas contra sus bentanas mayneles claraboyas y bidrieras que en muchos años no se an reparado y en diversas partes estan sus piedras demolidas eladas y quebradas y las paredes arcos y arbotantes que çiñen la dicha fabrica deteriorados por las partes mas altas medios y profundidad de sus fundamentos a que se deve ocurrir con toda brevedad preferiendo lo mas preçiso... 
La bóveda central del crucero amenazaba con caerse arrastrando tras de sí parte del edificio. Había que buscar una solución rápida, efectiva, acorde con la categoría del monumento y respetuosa con su historia. En febrero de 1631 el cabildo propuso pedir a la catedral de Oviedo que uno de sus maestros acudiera a solventar los problemas de la leonesa ${ }^{27}$. Fue elegido el santanderino Juan de Naveda, uno de los más reputados arquitectos del norte de España en la primera mitad del siglo XVII ${ }^{28}$, quien examinó el edificio y aconsejó la realización de una serie de obras urgentes $^{29}$. Los capitulares decidieron entonces hacer una cúpula, pero no sin antes tener vacilaciones sobre su conveniencia. En julio de 1632 resolvieron pedir consejo a varios maestros $^{30}$, entre los que se encontraba Juan del Aza, quien, al parecer, se mostró partidario de la novedad $^{31}$. Las obras comenzaron, pero pronto

-

A continuación hace Naveda una detallada enumeración de las obras más urgentes y necesarias que se debian emprender sin más dilación.

${ }^{27}$ A.C.L., Fondo General, doc. 9.954, fol. 32 r.:

Que se llame al maestro de Obiedo que vea las vobedas

Otro si acordo el cabildo se llame al maestro de canteria de la ciudad de Obiedo que venga a ber la vobeda desta santa yglesia para que declare que detrimento tenga y cuyde si se conçertare de su reparo

${ }^{28}$ Trabajó en la dirección de importantes obras de Cantabria, Asturias, Valladolid y Burgos, siendo también Maestro de las Obras Reales de la Costa del Cantábrico, así como Maestro mayor de la catedral de Oviedo y del arzobispado de Burgos.

${ }^{29}$ A.C.L., Fondo General, doc. 9.954 , fol. 39 v.

Maestro de Oviedo Juan de Nabeda.

Este dicho dia pidio liçencia Juan de Nabeda maestro de canteria uno de los quatro de su magestad asistente en Obiedo para entrar a ablar a los señores dean y cabildo en raçon de los defectos de las vobedas de la iglesia, maderas $y$ armaduras y abiendole oydo al sobre dicho y visto un memorial que de los defectos de dichas vobedas abia sacado, cometio el cabildo dicha proposición y memorial a los señores de diputaçion, administrador y consiliarios para que cuyden de lo que deba haçer de modo que dichas vobedas no bengan a mayor detrimento.

${ }^{30}$ A.C.L., Fondo General, doc. 9.954, fol. 70 v.:

A señores de fabrica, linterna y que se llamen maestros.

Cometiose a señores de fabrica hagan llamar los maestros de obra que les pareciere mas a proposito para ver la obras desta santa yglesia y si conbendra haçer una linterna sobre el crucero para que con su paresçer se escoja lo que fuere mas a proposito.

${ }^{31}$ A.C.L., Fondo General, doc. 9.954, fol. 75 v.:

Maestro de obra Juan de la Aza.

Cometiose a los señores administrador y consiliarios de la fabrica contenten a un maestro de obras que a bisto la obra y linterna que quiere haçer la yglesia y hizo memorial cerca de todo ello. Y que los dichos señores traten lo que mas conbendra haçer cerca de si se hara $u$ no dicha linterna y que de lo que les paresçiere den quenta al cabo para que escoxan lo mejor. fueron paralizadas para solicitar nuevos informes sobre la viabilidad del proyecto, a la vista de las dificultades surgidas en la fábrica ${ }^{32}$. Una vez examinados las distintas sugerencias, el cabildo, tras una votación, decidió que el crucero siguiera cubierto con bóveda de crucería, conforme estaba originalmente ${ }^{33}$. Todo parece indicar que la novedad produce reticencias en los capitulares que no se atreven a dar el paso para incluir un nuevo lenguaje arquitectónico en la catedral. Sin embargo, el persistente Juan de Naveda compareció poco tiempo después de nuevo ante el cabildo y le convenció definitivamente para hacer una gran cúpula con linterna en el crucero, e incluso los capitulares más decididos no dudaron en hacer donaciones personales para acelerar los trabajos que pretendían la definitiva modernización del templo ${ }^{34}$. La

32 A.C.L., Fondo General, doc. 9.955, fol. 5 v.:

Determinose con acuerdo y pareçer de la diputacion geneal y de fabrica que se adereçen los texados de la iglesia y lo demas de la obra de la boveda y arco se suspenda ansi lo de la canteria y labrar piedras como lo demas de dicha obra y que se llame persona o personas maestros de obra que bean la obra si a de haçerse de nuebo rompiendo todos sus cuatro arcos recintos segun queria executar el maestro Nabeda ...lo que determinare ser mas conbeniente el dicho maestro Naveda lo ponga en execucion, y a señores diputados y de fabrica se comete el llamar el maestro o maestros que les pareciere ser mas a proposito para ver dicha obra

33 A.C.L., Fondo General, doc. 9.955, fol. 14 v.:

...Votose y salio acordado que el maestro Naveda haga y execute la obra como tiene determinado no haçiendo la linterna sino haciendo la obra conforme estaba el crucero desta santa yglesia.

${ }^{34}$ A.C.L., Fondo General, doc. 9.955, fol. 76 v. y 77 r.:

Juan de Nabeda ynformo en raçon de la obra de la yglesia

Que se aga la media naranja y linterna.

Este dicho dia entro en cabildo Juan de Nabeda maestro de canteria a ymformar de la obra que se abia de açer y el coste que podria tener sis se hiciese media naranja y lanterna y de su lucimiento y como abia batante fortaleça para sustentarlo. Dijo que el coste que se haria determinandose el cabildo a haçer dicha media naranja y lanterna que seria de çinco a seys mil ducados y que seria muy luçida y que el se obligaria de haçerla por lo dicho y abiendole oydo se proçedio a votar si se ara dicha media naranja y lanterna por aba blanca y negra declarando el señor primiciero las abas diciendo que la aba blanca es que se aga la lanterna en la forma dicha y la negra que se execute lo acordado por el cabildo por su auto capitular y abiendo todos votado por su orden y regulados los votos y abas salio aba blanca por do fue visto ordenar el cabildo que se hiciese la media naranja y lanterna y algunos señores ofrecieron limosna pagada la cantidad en dos años para dicha obra y consintieron que desde luego quedase librado en las planas las quales se pondran al fin deste cabildo declarando la cantidad que cada uno ofrecio. Y determino el cabildo que el señor administrador de fabrica sacase liçençia para que se pidiese por el obispado para haçer dicha obra... 
medida esperaba resolver el problema estructural e incorporar al mismo tiempo a la catedral uno de los elementos más característicos y prestigiosos de la arquitectura del barroco. En la singular decisión no estaba ajeno el deseo de emulación con otras catedrales del entorno que estaban construyendo una gran cúpula sobre el crucero, o al menos tenían proyectado hacerla, actitud que se puede considerar habitual en aquellos años ${ }^{35}$.

En el siglo XVII los arquitectos intuían que las catedrales eran en realidad el resultado de una interacción de obras y estilos; por lo tanto, no resultaba ofensiva una superposición de formas, dando cada uno de esta manera autonomía a su propuesta estética ${ }^{36}$. Así, Juan de Naveda diseñó una monumental cúpula sobre pechinas y rematada con una linterna, con todas las características de la Edad Moderna, para ser colocada directamente sobre la estructura gótica previa, lo que pronto demostró ser un grave error técnico, pero que no se cuestionaba estéticamente y se aceptaba ideológicamente (lám.1). La construcción empezó enseguida, poniéndose el mismo proyectista al frente de los trabajos ${ }^{37}$, razón por la cual fue nombrado al poco tiempo maestro de obras de la catedral de León ${ }^{38}$, cargo

Memoria de los señores prebendados dignidades y canonigos que mandaron limosna a la fabrica desta santa yglesia para la obra de la media naranja y lanterna que el cabildo acordo se hiciese en el crucero de la nao mayor consintiendo dichos señores que lo que cada uno mandase quedase desde luego librado en sus planas pagando dicha cantidad dentro de dos años...

${ }^{35}$ A. RODRÍGUEZ G. DE CEBALlOS, "Arquitectura y urbanismo del siglo XVIII", en Historia del Arte de Castilla y León, t. VI, Valladolid, 1997, p. 174.

${ }^{36}$ V. TOVAR MARTín, El arte del barroco..., p.114.:

${ }^{37}$ Las propuestas de Naveda se recogen en varios documentos. Véase principalmente, A.C.L., Fondo General: doc. 11.004, 11.009, 11.039; véase D. DE LOS Ríos, ob. cit, pp. 20-25; E. DÍAZ-JIMÉNEZ Y MOLLEDA, Catedral de León. La cúpula del siglo XVII y la linterna del XVIII, Madrid, 1931; J. RIVERA BLANCO, Historia de las restauraciones de la catedral de León, Valladolid, 1993, pp. 72-75.; E. MoRAIS VALLEJO, Aportación al barroco..., p. 310-312.

38 ACL Fondo Geneal, doc. 9.960, fol. 78 r.:

Naveda architecto de esta santa yglesia

Refirio el sr. procurador el pareçer de la diputacion sobre las peticiones que le estaban cometidos y en quanto a la de Juan de Naveda architecto que pedia se le diese titulo de serlo de esta santa yglesia con asignacion de salario y liçençia para ir a su tierra y ayuda de costa, fue el pareçer se le diese dicho titulo y en quanto al salario se cometio el ver el que sea acostumbrado a dar y se refiera para tomar resoluçion el cabildo y ver las condiçiones con que se aya de haçer la escritura y aprobose por el cabildo dicho pareçer, y en quanto a la licençia para hacer ausencia fue de que compatibilizaba con el de architeto mayor de las obras de su magestad, según consta en la documentación ${ }^{39}$.

Ante la trascendencia de la obra y el posible peligro de que toda la fábrica se quebrara, se solicitaron informes con el fin de evaluar la seguridad del proyecto. Uno de ellos fue el realizado en 1634 por un arquitecto llamado en la documentación como Padre Maestro de Ávila. Este dio por buena la construcción, al considerar que los cuatro pilares destinados a sostener la media naranja eran lo suficientemente sólidos como para contrarrestar los empujes de la nueva cubierta; no obstante dejó instrucciones escritas con ciertos consejos para mejorar la edificación. Además, también informó favorablemente de la actividad del director de la obra, en vista de lo cual el cabildo, respaldado en su decisión, determinó seguir con la construcción $^{40}$. Este arquitecto, del que la documentación no explicita su nombre, sería con toda probabilidad el maestro mayor de la catedral de Ávila entonces, en lo que parece ser un nuevo intercambio de arquitectos entre catedrales.

que se le diese el pareçer y el cabildo lo tomo por bien encargandole venga a tiempo para proseguir la obra. Y en quanto a la ayuda de costa le paresçio a la diputacion se le diesen por ahora quatrocientos reales, votose dicho parecer juntamente con el darle el titulo de maestro de dichas obras diçiendo el señor primiciero que la haba blanca era vista que se le daba dicho titulo en la forma dicha y asimismo los dichos quatrocientos rs. de ayuda de costa, y regulados los votos fueron mas de las dos partes de las habas blancas con que fue visto aprobar dicho pareçer en ambas cosas.

39 A.C.L., Fondo General, doc. 11.004, s./f.:

Juan de Naveda architeto mayor de las obras de su magestad y maestro de las que V. Sa tiene en esta Sancta Yglesia por titulo y merçed que $V$. $S^{a}$ se sirvio de açerme.

40 A.C.L., Fondo General, doc. 9.956, s/f.:

Padre Maestro de Abila dio quenta al cabildo de lo que se debe hacer en las vobedas

Memorial para que la obra se execute.

Este dicho dia entro en cabildo el Padre maestro de Abila que vino a ber la fabrica de la media naranja y lanterna y abiendo hecho y dicho su raçonamiento en satisfaçion de la firmeça que para sustentarla tienen los pilares fundamentales, dijo tenia grande satisfaçion del maestro que la haçe y que para mejor se execute dejara un papel en poder del señor canonigo Alonso de Yglesias administrador al tenor del qual se executara dicha obra y abiendo el cabildo dado las gracias al padre maestro por la merced reçibida ordeno que la obra se haga como se ha dicho y que al maestro se le de las graçias por ello y que al padre maestro de Abila se le gratifique su trabajo para lo qual se cometio plenariamente a la diputacion vean lo que les pareçe se le podra dar y lo que les pareçiere desde luego quede librado. 
Cuando la cúpula estaba muy avanzada, Naveda murió y se interrumpieron las obras durante muchos años. La conclusión se demoró hasta bien entrado el siglo XVIII, tanto por cuestiones económicas como técnicas, ya que pronto se puso de manifiesto la inadecuación de la cúpula con el sistema constructivo gótico. A partir de ese momento se sucedieron toda una serie de arquitectos que trataron de encontrar la mejor solución, pero siempre con la premisa de conservar la cúpula; a nadie se le ocurrió desmontar lo hecho y cambiarlo por una bóveda de crucería como estaba en su origen. El primero fue Manuel Conde Martínez, vecino de Aguilar de Campoo ${ }^{41}$, quien en 1694 hizo el proyecto de una linterna para cerrar la cúpula inconclusa, aunque finalmente no fue llevado a la práctica ${ }^{42}$ (lám. 2)

En 1711 fue contratado Pantaleón del Pontón Setién, por aquellos años maestro mayor de la catedral de Salamanca ${ }^{43}$, para culminar las obras $^{44}$. Su proyecto, fechado un año antes, no sólo aportaba soluciones técnicas, disponiendo la construcción de cuatro pilastrones para asentar bien la estructura, sino que también se preocupaba por los valores plásticos dando una importancia decisiva a la decoración. En su propuesta aparecen pilastras de orden compuesto, lunetos tallados en el casquete y adornos con relieves para dar mayor apariencia de riqueza al conjunto $^{45}$. En su diseño influyó la colaboración

${ }^{41}$ Manuel Conde Martínez llegó a León contratado por el cabildo para hacer la linterna de la cúpula. Posteriormente realizó el hastial sur del crucero. Fue maestro de obras de la catedral leonesa desde 1694 hasta principios del XVIII, trabajando en diversas obras de la diócesis, según se recoge en varios documentos. Véase por ejemplo, Archivo Histórico Diocesano de León (desde aquí A.H.D.L.), Protocolos de Antonio Ibáñez de la Madrid, ${ }^{\circ}$ 85, c. 56, fols. 65 y ss.; Archivo Histórico Provincial de León (desde aquí A.H.P.L.), Protocolos de Francisco de Castro, caja 312, leg. 509 , fol. 419.

${ }^{42}$ Los dibujos de la planta y el alzado de la linterna se conservan en el A. C. L.

${ }^{43}$ E. Llaguno y Amirola, E., Noticias de los arquitectos y arquitecturas de España desde su restauración, Madrid, 1829, t. IV, p. 185; F. SOJO Y LOMBA, Los maestros canteros de la Trasmiera, Madrid, 1935, p. 172; M. C. GONZÁlEZ ECHEGARAY y otros, ob. cit., p. 518; F. CHUECA GoITIA, La catedral Nueva de Salamanca, Salamanca, 1951, p. 177 y ss.

${ }^{44}$ A.C.L., Fondo General, doc. n ${ }^{\mathrm{o}} 11.039$ y 11.040 , s//f. Las condiciones para hacer la linterna, las posturas que se hicieron y las fianzas dadas para la obra, se recogen en: A.H.D.L., Protocolos de Antonio Ibáñez de la Madrid, $\mathrm{n}^{\circ}$ 94 , c. 65 , fols. $78-82$.

45 A.C.L., Fondo General, doc. no 11.040, s/f:: de otro reconocido arquitecto del momento, fray Pedro Martínez de Cardeña ${ }^{46}$, quien, invitado también por el cabildo, realizó una traza para levantar una linterna muy decorada, que después aquel utilizó para su proyecto ${ }^{47}$.

Otro maestro de la catedral de Salamanca, que emitió un nuevo informe favorable sobre la oportunidad de levantar la linterna así como de la forma de hacerla, fue Joaquín de Churriguera $^{48}$, quien dio su opinión en $1712^{49}$. Recor-

...e resuelto en medio de mis ocupaciones ofrezer ejecutarla con dichas alturas y adornando las enbecaduras de las pilastras ynteriores con festones y rompiendo unos capiteles compuestos y tallando los lunetos de la media naranja y en su clave un floron y algun otro adorno de escoltura y en lo esterior disposizion que el todo aga tan hermoso que corresponda a lo mejor de dicha santa yglesia en su respecto = Y asi mismo se ejecutara una caja quadrada proporzionada a pedestral con agradable sotabasa y basa en lo que se bea, y dicha caja se coronara con un cerrador que corresponda al que tiene la nabe mayor repartiendole algunas aguatoches y remates en sus claros, y asi mismo en la ultima pieza de dicho pedestral disposizion de acoductos para que reziban la agua que el tejado que debe hacerse de la media naranja echa resultase este pedestral y remates y corredores en el todo yndependiente de la linterna: todo lo ejecutare dandome canteras seguras y la madera y demas despojos de la linterna demolida, menos lo que corresponda a bidrieras y las maderas y herramientas que tenga en ser dicha santa yglesia... Leon, abril veinte y tres de mil setezientos y diez $=$ Pantaleon del Ponton Septien...

46 Tuvo una amplia actividad tanto teórica, como práctica. Llevó la maestría de las catedrales de Salamanca, Oviedo y Valladolid y también estuvo en las obras de los monasterios de Cardeña, Nuestra Señora de Prado, San Benito y Silos, entre otros trabajos. Sobre su vida y obra se puede consultar, E. LlagunO Y AMIROLA, Noticias de los arquitectos y arquitectura de España desde su restauración, Madrid, 1829, pp. 118-122.

47 A.C.L. Fondo General, doc. $n^{\circ} 11.039$, s./f.:

..poco despues de haver llegado a Salamanca y antes de aber puesto formalmente en planta la obra de la linterna como tenia conzibido desde el prinzipio y espreso a $V$. $S^{a}$, se le remitio una traza de un religioso benyto que tiene agradables sombras y hermosean por la oposizion que hazen a lo blanco y vastantes cavezas de serafines en cuya vista le parezio por el punto de su arte, y al mayor desempeño con $V$. $S^{a}$ hazer otra traza en que sin apartarse de su ydea en la solidez y firmeza de la obra yziese tambien agradable vista $y$ hermosura añadiendo que los estrivos y arcos se adornasen de molduras, escultura y talla, espejos, volutas con chicotes y dar mas ancho a los arcos y otras cosas..

El denominado "religioso benito" en el documento es sin duda Pedro Martínez, pues en un memorial de 1734 se hace mención a las ...disposiziones dadas por fr. Pedro Martinez de Cardeña del horden de San Venito, A.C.L. Fondo General, doc. n $\mathrm{n}^{\circ}$ 11.005/1, s./f; también lo afirma así E. DÍAZ JimÉnEZ Y MOLLEDA, "La catedral de León, la cúpula del siglo XVII y la linterna del XVIII, Erudición Ibero-Ultramarina, $\mathrm{n}^{\circ} 8$, Madrid, 1931, pp 488-525.

48 Joaquín Churriguera fue maestro de la catedral de Salamanca entre 1713 y 1724, véase, F. CHUECA GOITIA, La catedral Nueva de Salamanca, Salamanca, 1951, p. 177 y 
damos que éste realizó el remate de la torre norte en $1713^{50}$, probablemente el cabildo le encargó la reparación de la coronación de la torre aprovechando que estaba en León para realizar el estudio del estado de la cúpula ${ }^{51}$.

Pontón Setién tampoco llegó a terminar el cierre del crucero, siendo su mayor aportación la construcción de los cuatro pilastrones alrededor de la cúpula, que en realidad no hicieron sino aumentar aún más los desequilibrios que pretendía solucionar ${ }^{52}$. Después de su defunción, acaecida en 1713, se paralizaron de nuevo las obras y se despidieron a muchos artífices, los cuales tuvieron que volver a su lugar de origen al quedarse sin trabajo ${ }^{53}$. En ese momento era necesario nombrar otro maestro para proseguir con la fábrica de la catedral. Juan de

ss.; A. CASASECA CASASECA, Las catedrales de Salamanca, León, 1993, p. 70 y ss.; A. RodRíguez G. DE CEBALlos, Las catedrales de Salamanca, León, 1978; ÍDEM, "Las catedrales de Salamanca", en Medievalismo y neomedievalismo en la arquitectura española: Las catedrales de Castilla y León, Ávila, 1994, pp.157-159.

${ }^{49}$ Consta un pago a Churriguera por su labor en el asunto de la linterna en: Memorial de Pantaleón del Pontón Setién sobre la obra que está haciendo en la media naranja de la catedral, A.C.L. Fondo General, doc. $\mathrm{n}^{\circ} 11.039$, s./f,

Quenta del gasto en la obra de la linterna que se está ejecutando en la santa yglesia de Leon y de lo que falta para su conclusion ...En diferentes gastos, asi con Churriguera y un tallista que vino de Salamanca y enfermo en esta ziudad, como otros que se an ofezido en el discurso de los tres años... 3.600 reales.

${ }^{50}$ Sabemos que el encargado de la obra fue Churriguera por un papel encontrado en la bola de la veleta, que decía, según transcripción de D. DE LOS Ríos, ob. cit., p. 31: ...habiéndose levantado la aguja de esta torre diez y ocho pies más de alto que lo que antes tenía, siendo Maestro Don Joachin de Churriguera, Maestro que al presente estaba fabricando de nuevo la Santa Iglesia de Salamanca...

51 J. RIVERA BLANCO, Historia de las restauraciones..., p. 149, afirma que Churriguera visitó la catedral leonesa varias veces en el año 1714.

${ }^{52}$ D. DE LOS RÍOS, ob. cit..., t. II, p. 30, y E. DÍAZJiMÉNEZ MoLleDA, La catedral de León..., p. 500, atribuyeron la construcción de los cuatro pilastrones a Churriguera, sin ningún fundamento. Al ser levantados durante la maestría de Pontón Setién, es lógico atribuírselos a él. Así lo afirma J. RIVERA BLANCO, Historia de las restauraciones..., p. 103.

53 A.C.L. Fondo General, doc. n ${ }^{\circ} 11.039$, s./f., recoge el nombre de algunos de estos escultores::

...Franzisco de el Hoyo, Joseph de las Cajigas, Bernardo de la Castañeda y Bernardo de Lombera, maestros escultores y tallistas a cuio cargo puso don Pantaleon del Ponton, maestro de la obra de V. I., todo lo que en ella se obrase de este arte y facultad... reconoziendo la ynposivilidad de que en este mes ni en los demas que se le siguen de este año se pueda concluir ni fenecer... nos allamos resueltos a retirarnos a nuestras casas...
Velasco Pontón, sobrino del difunto y maestro arquitecto de cantería, se propuso para el cargo, alegando que conocía bien la fábrica, pues había asistido a su tío desde el principio ${ }^{54}$. Pero esta razón no era suficiente garantía para el cabildo que no tuvo a bien contratarlo; desde el inicio había apostado por maestros consolidados y no era momento ni circunstancia, a la vista de la gravedad de la situación, de rebajar las pretensiones y arriesgarse con un novel.

Por esta razón, el cabildo llamó a Fernando de Casas y Novoa, al efecto maestro de obras de la catedral de Santiago de Composte$1 \mathrm{l}^{55}$, quien hizo un detallado estudio de los errores que se apreciaban en la cúpula obrada por Juan de Naveda. Su opción era desmontarla, aunque únicamente por razones técnicas, no por cuestiones formales o de contraposición de estilos, pues aconsejaba realizarla de nuevo con mayor seguridad. A las mismas conclusiones llegó el arquitecto leonés Andrés Hernando cuando emitió su dictamen, junto con el anterior, en $1714^{56}$.

Posteriormente, los maestros arquitectos leoneses Felipe Álvarez de la Viña, José Álvarez de la Viña y Pedro de Valladolid, hicieron un reconocimiento de la obra y elaboraron un espediente, redactado en 1734, en el que hicieron un estudio del estado de la cúpula, así como un prolijo relato de los desperfectos y las obras que consideraban más necesarias para salvar la estabilidad de la catedral. En él reconocen la valía de los arquitectos que habían trabajado en

54 A.C.L. Fondo General, doc. $n^{o} 11.039$, s./f.

...Juan de Velasco Ponton, maestro arquitecto de canteria, puesto a los pies de V. Ilma, digo que de mandado de don Pantaleon del Ponton, mi tio, he asistido desde su prinzipio asta el estado que oy tiene a la fabrica de la linterna de la santa yglesia, y mediante aver sido Dios servido de llevarle sin averla ultimado, deseando el logro de dicha fabrica y que la disposizion de dicho mi tio tenga efecto en el servicio de V. Ilma., me ofrezco el fenezerla pagandome los ofiziales y sin mas interes que el de servirle en quanto me mandare, y teniendo el logro del azierto remito a la grandeza de V. Ilma. la satisfazion de mi travajo quedando siempre con la obligazion de lo mucho que debio mi tio a la generosidad de V. Ilma. (Firma y rúbrica de Juan de Velasco Pontón).

55 Sobre la obra y la personalidad de este arquitecto, véase principalmente, X. M. GARCÍA IGLESIAS, Fernando de Casas Novoa, Santiago de Compostela, 1993.

${ }^{56}$ A.C.L., Obra de la linterna sobre la media naranja de la catedral. Declaración de maestros que la dan por no segura, A.C.L., Fondo General, doc. 11.038. El documento fue transcripto por E. DÍAZ-JIMÉNEZ Y MOLLEDA, La cúpula del siglo XVII..., pp. 19-25. 
el cierre del crucero, pero también relatan los graves problemas de construcción encontra$\operatorname{dos}^{57}$.

Un nuevo dictamen, ahora del afamado Narciso Tomé, maestro mayor por entonces de la catedral de Toledo, vuelve a dar cuenta de las deficiencias de la cúpula y de la necesidad de rematarla cuanto antes con una linterna para cerrar el hueco. Aconsejaba que se hiciera de madera, con el fin de que tuviera menor peso, habida cuenta de la debilidad de la sustentación, pero recubierta de estuco pintado imitando piedra, con la intención de no desentonar con el resto del conjunto ${ }^{58}$.

Pese a todas estas advertencias y a los reiterados estudios que denunciaban el peligro que

\section{-}

${ }^{57}$ A.C.L. Fondo General, doc. $\mathrm{n}^{\mathrm{o}} 11.005 / 1$, s./f.:

Memorial que se dio al rey nuestro señor por el cabildo desta iglesia, suplicando se sirva de arbitrar algun socorro para poder emprender la obra de la media naranja. Año de 1733.

Declaracion de los maestros

En la ziudad de Leon a 16 dias de el mes de febrero de 1734 el Sr. Dn. Diego Navarro, correjidor intendente de ella por ante mi el escrivano tomo y recivio juramento por Dios Nro. Sr. y una cruz en forma de derecho de Phelipe Alvarez de la Viña, Joseph Alvarez de la Viña y Pedro Valladolid, maestros arquitectos nombrados para las dilijencias que contienen estos autos y reconocimiento y tasazion y regulazion de las hobras prezisas de la Santa Yglesia Catedral desta dicha ciudad y aviendo jurado prometieron decir berdad y para efecto de hacer su declarazion por mi el escribano, se les bolvio a leer a la letra la real provision de su magestad y señores de su real Consejo de Castilla....

Primeramente, en el reconocimiento de la media naranja de dicha Sta. Yglesia Cathedral, declaramos que esta se alla cubierta con tosco tejado y su fabrica asta el paraje de elijir la linterna que sobre ella se a yntentado diferentes bezes fabricar, por artifizes escojidos entre los mejores que se an allado en estas comarcas, como an sido Don Pantaleon del Ponton, Don Juachin de Chorriguera y disposiziones dadas por fr. Pedro Martinez de Cardeña del horden de San Venito y las de Manuel Conde Martinez, y al fin $y$ ultimo las de Fernando de Casas y Noboa maestro de la catedral de Santiago, las quales tubimos presentes y todas ellas fueron ejecutadas al fin de poder aprovechar dicha media naranja y conseguir la fabrica de la linterna...

${ }^{58}$ A.C.L., Fondo General, doc. no 8.780, fols. 3-6 r.:

...por lo que no soi de sentir se pueda seguir con esta obra segun esta delineada, y solo podra resistir dicha media naranja de la forma que esta, el azer la linterna de estuque ymitando a la piedra por lo ynterior, y por lo exterior aziendola de madera y enpizarrada = y aunque esto pudiera quedar con luzimiento y seguridad, asi por lo esterior como adornada por lo ynterior y que a la bista parezeria piedras $y$ con bastante duracion, y adornada la media naranja con toda seguridad por lo ynterior de forma que quedase con bastante luzimiento, solo se ofreze el reparo de la disonancia que ara por lo exterior por el enpizarrado, siendo todos los remates de la yglesia de piedra, asi en torres como todos los demas de que se conpone corría la estabilidad de la catedral, el cabildo no quería renunciar a la cúpula. Parecía estar más preocupado por conservar este elemento barroco, contrario a las estructuras medievales sobre las que se apoyaba, que por solucionar los problemas estructurales que generaba. Esta es la razón por la que nos hemos detenido en la relación de los informes en los que siempre se habla de la manera de mantener la cúpula y nunca de dar marcha atrás, hacia la forma antigua.

Por fin llegaría la solución definitiva con un extranjero, el arquitecto y decorador italiano Giacomo Pavía ${ }^{59}$, que llegó a la ciudad de León en el año $1745^{60}$, acompañado de otro compatriota suyo, Juan Campani Bonabera ${ }^{61}$. Su participación en la catedral leonesa fue providencial, cerrando la cúpula iniciada por Naveda pero también arreglando las capillas del Carmen y de Nuestra Señora del Dado, que amenazaban con arruinar otras partes del edificio ${ }^{62}$, además de realizar otras actuaciones, como veremos más adelante.

Pavía ideó una solución más escenográfica que arquitectónica, propia de su formación $y$ actividad $^{63}$, cerrando por fin en 1745 la cu-

${ }^{59}$ Fue uno de los italianos que llegaron a España en el siglo XVIII con la nueva dinastía borbónica, en su deseo de renovar la arquitectura tradicional española. Era académico de la Clementina de Bolonia, y en 1744 fue nombrado Maestro Director con ejercicio en la Junta Preparatoria de la Real Academia de Bellas Artes de San Fernando. Sobre este arquitecto véase, A. QUINTANA MARTÍNEZ, La arquitectura y los arquitectos en la Real Academia de Bellas Artes de San Fernando (1744-1774), Madrid, 1983, p. 142.

${ }^{60}$ A.C.L., Fondo General, $n^{\circ}$ 9.678. Libro de asiento de las libranzas..., fol 190::

...maestro don Jacobo de Pavia entro en esta ciudad el dia primero de marzo de 1745

${ }^{61}$ Ídem, fol. 191:

...mas diez doblones en oro que componen setecientos y cinquenta y dos reales y 32 maravedies vellon entregados en Madrid de orden del señor administrador Escobar a Juan Campani compañero de dicho don Jacobo y de orden de el mismo y de que no se a sacado libramiento.

En 5 de noviembre de 1745 dio el señor don Diego de Escobar tres mil trescientos y doce reales y treinta y dos maravedies que lo componen quarenta y quatro doblones de oro a don Jacobo Pavia en una letra dada por el sr. dn. Thomas Gutierrez de Vidanes contra el sr. arzediano de Triacastela en favor de Juan Campani Bonabera, residente en la corte que fue para quien la pidio el dicho don Jacobo...

62 J. RIVERA BLANCO, Historia de las restauraciones..., p. 136

${ }^{63}$ El boloñés Giacomo Pavía llegó a España precedido de su fama como escenógrafo y decorador de representaciones operísticas y teatrales. Aunque vino a España para realizar esos trabajos, desplegó una importante actividad 
bierta con una linterna de madera, decorada con pan de oro y exteriormente recubierta con plo$\mathrm{mo}^{64}$. Con su actuación se terminó la cúpula y se consiguió modificar el espacio interior de la catedral con la adición de un elemento nuevo y distintivo, que culminaba, aunque después de mucho tiempo, la primera transformación del espacio interior de la catedral, pero que no lograba resolver el grave problema constructivo de la zona del transepto.

Curiosamente son muy pocos los testimonios llegados hasta nuestros días para que podamos hacernos una idea de la configuración de la cúpula. $\mathrm{Su}$ aspecto exterior se puede adivinar en algunos grabados de época ${ }^{65}$, o por la reconstrucción infográfica hecha con motivo del centenario de la restauración decimonónica ${ }^{66}$. Del interior, aparte del trabajo infográfico, sólo se conocen dos documentos interesantes, uno es el grabado de M. Navarro y F. Sánchez Pertejo $^{67}$, y el otro es la descripción que hace de ella Demetrio de los Ríos, desde una postura beligerante con la estética barroca ${ }^{68}$. En cualquier

arquitectónica, llegando a ser profesor de arquitectura en la Academia. Cf. J. URREA FERNÁNDEZ, La pintura italiana del siglo XVIII en España, Valladolid, 1977, pp. 41 y 170175.

${ }^{64}$ A.C.L., Fondo General, doc. 9.678, fols. 163 y 164 r: Obra del cupulino

.. en 14 de Junio de 1745 libre a Domingo Fernandez y compañeros vezinos de Prioro de 219 tablas de roble 505

... en 15 de Julio de dicho año libre a Don Joseph Fernandez cura de Villamoros cien rs vellon de quatro carros de negrillo que se le compraron para el cupulino .......... 100

... en 8 de Julio de 1745 libre a los Maragatos que trajeron el plomo para cubrir el cupulino $1.876 \mathrm{rs}$.

en 20 de agosto de 1745 libre a Joseph Collado vezino de Valladolid 1.400 rs vellon de 10.000 panes de oro que remitio para el cupulino a razon de 140 rs. el millar

..en 14 de septiembre de 1745 libre a Don Damaso 828 rs. de 46 dozenas de vidrio blanco a 18 rs. cada uno ....... 828

..en 4 de octubre de 1745 libre en dicho D Damaso 1.089 rs para pagar a Tabares181@y15 libras de plomo en plancha que trajo de Madrid para el cupulino y es solo el porte .....1.089

${ }^{65}$ J. M. QUADRADO, Recuerdos y bellezas de España. Asturias y León, Madrid, 1855; J. GARCíA DE LA FOZ, Crónica general de España. Provincia de León, Madrid, 1867.

${ }^{66}$ Véase el catálogo de la exposición La catedral de León. El sueño de la razón, León, 2001, p. 135.

${ }^{67}$ Publicados en M. Risco, Iglesia de León y monasterios antiguos y modernos de la misma ciudad, Madrid, 1792 (ed. facsímil, León, 1978).

${ }^{68}$ D. DE LOS RÍOS, ob. cit..., p. 23.: ...pechinas decoradas con las colosales figuras de los Santos Padres dentro de lineas torcidas o de mal gusto. Sobre estas cuatro pechinas caso, escasos elementos para hacer un estudio morfológico y estilístico, y más si tenemos en cuenta que desconocemos su grado de fidelidad con la realidad (lám. 1).

La cúpula se mantuvo en pie hasta que Matías Laviña la desmontó en 1861 dentro del proceso de restauración general que sufrió la catedral leonesa a finales de dicho siglo, con dos intenciones; una era solucionar el problema constructivo del crucero, la otra era eliminar el elemento barroco que se consideraba disonante ${ }^{69}$

La segunda gran obra de la que hablamos al referirnos a la transformación del espacio interior, fue la realización de un grandioso retablo para la capilla mayor ${ }^{70}$. Hasta entonces había uno de finales del gótico, con buenos lienzos de Nicolás Francés, que ya no satisfacía a los intereses del cabildo ${ }^{71}$. Hubo varios intentos de sustituirlo durante el siglo XVII, incluso José de Margotedo llegó a realizar unas trazas para ello y después Juan de Medina Argüelles hizo otras, que tampoco se llevaron a cabo $^{72}$. Las razones esgrimidas para sustituir por fin el retablo del maese Nicolás por otro de nueva factura fueron tanto de carácter estético, a con-

fabricó el anillo, que no era muy alto, sino con las dimensiones y molduraje de una regular cornisa, no omitiendo en su arquitrabe y friso sobre los vértices de los arcos torales medallones o cartelas propias de la época. Sobre esta anular cornisa volteó la media naranja en buenas condiciones constructivas y ornada interiormente con nichos simplemente figurados, medallones circulares y rehundidos de varias formas, distribuido todo esto en compartimentos por medio de fajas que, partiendo del anillo inferior, confluían en el superior o de la linterna. Para las hornacinas se esculpieron estatuas de Doctores, en los medallones se representaron ocho sibilas y mujeres biblicas, y se tallaron ornamentos diversos en los rehundidos. En orden a la linterna, sobre su correspondiente anillo alzábanse en ocho caras otros tantos intercolumnios de arcos apuntados como compartimentos tenía debajo la bóveda sustentando su cornisa circular, y sobre ella otra pequeña media naranja con un alto remate coronado por una bola y una cruz.

69 Sobre el desmonte de la cúpula hecho por Matías Laviña véase: I. GONZÁLEZ-VARAS, La catedral de León..., pp. 132-139; ÍDEM, "El debate sobre la recuperación ideal..., pp. 251-268; J. RIVERA BlanCO, Historia de las restauraciones..., pp.171-193.

${ }^{70}$ Una aproximación a las vicisitudes de los retablos de la catedral se encuentra en F. ÁlvAREZ, "La pulchra leonina y su retablo de la Capilla Mayor", Archivos Leoneses, $\mathrm{n}^{\circ} 12$, León, 1952, pp. 95-109.

${ }^{71}$ Una descripción detallada del retablo de Nicolás Francés, escrita en el siglo XVIII, se encuentra custodiada en A.C.L., Fondo General, doc. 1.801, s/f.

${ }^{72}$ F. LLAMAZARES RODRÍGUEZ, El retablo barroco en la provincia de León, León, 1991, pp. 362. 
secuencia del cambio del gusto, como de deterioro del antiguo ${ }^{73}$, aunque, eso sí, reforzadas con una coartada litúrgica e ideológica por considerarlo la parte principal del culto. Así queda explicitado en una carta dirigida por el cabildo al marqués de Astorga $^{74}$, eminente benefactor de la catedral, en la que se le pide dinero para sustituir el viejo retablo, al que tildan de viejo y estropeado, y por tanto inservible e indecoroso para una catedral de la categoría de la leonesa ${ }^{75}$. El retablo había pasado a ser en el barroco una pieza fundamental de los templos, adquiriendo unas dimensiones y una riqueza artística impensables hasta el momento. La escenografía desplegada en los retablos no sólo se utilizaba para explicar el dogma por medio de imágenes, sirviendo de apoyo tanto para la predicación como para la oración, sino que también cumplía la misión de dar el máximo protagonismo al tabernáculo, soporte del culto a la eucaristía, según recomendaba encarecidamente el concilio de Trento $^{76}$.

Para llevar a cabo el proyecto, acorde con lo que hemos ido viendo, se pensó en el más célebre retablista del momento, recayendo la

-

73 ACL, Fondo general, doc. 8.780, fol. 7:

..Los señores Dean y Cabildo desta santa yglesia, aviendo determinado mandar vajar el retablo antiguo de la capilla maior por considerar hallarse las pinturas de que se componia (aunque primorosas y costosas mui desluzidas) escrivieron a la santa yglesia de Toledo permitiese que don Narciso Thome maestro arquitecto de ella viniese a reconocer el sitio y a acer diseño para la execuzion de nuevo retablo...

${ }^{74}$ El marqués de Astorga era un personaje destacado para la catedral leonesa, no en vano tenía silla en el coro de la catedral por privilegio inmemorial, véase A. LOBERA, Grandezas de la muy antigua e insigne ciudad e iglesia de León, Valladolid, 1596 (ed. transcripta, León, 1987), p. 52.

${ }^{75}$ A.C.L., Fondo General, doc. n ${ }^{\circ} 8.780$, fol. 2.

Al marqués de Astorga, con motibo de la obra del retablo, estando embajador en Roma.

...En el retablo se conserban muchas y muy gloriosas memorias de la Exma. casa de V. Exma. que manifiestan la magnificiencia y cariño que tubieron sus gloriosos progenitores a esta sancta yglesia

Esta tan antiguo y desluzido el retablo que es injuria de todo lo demas de este singular y ermosisimo edificio, debiendo ser lo mas sobresaliente por ser lo principal del culto y religion, si $V$. Exa. no ocurre a esta pretension totalmente nos hallamos sin medios y con sumo desconsuelo de perder esta ocasion, hallandose V. Exa. en ese puesto que unicamente puede con eficacia ynfluir en la execucion de tan sancta y justa obra que deseamos con ansia para reflejar en ella la mayor posteridad de su persona y casa.

${ }^{76}$ Sobre este tema remitimos a J. J. MARTín GONZÁLEZ, El retablo barroco en España, Madrid, 1993, p. 5 y ss., que trata el significado del retablo barroco para la ideología del momento y su función en la liturgia. elección en Narciso Tomé, maestro de la catedral de Toledo y afamado, no sin controversia, por ser el autor del innovador transparente de la girola de la catedral primada. Para León ideó un retablo con todas las galas propias del autor, pretendiendo ser el más grandioso de todas las catedrales españolas ${ }^{77}$. Contaba con una alambicada estructura arquitectónica, propia del barroco más castizo, en la que se acomodaban esculturas, pinturas, $y$, como no, la estructura que le hizo famoso, un transparente ${ }^{78}$. Con semejante máquina culminando la capilla mayor, el cabildo proseguía con el programa de transformación del interior de la catedral, ya que el nuevo retablo aportaba riqueza decorativa a la cabecera del templo y generaba una sensación de movimiento en esta zona que contradecía la planitud y pobre estructura del antiguo (lám. 3 y 4). Podemos afirmar que el diseño de Tomé otorgaba verdaderamente una apariencia distinta al espacio catedralicio, cambiando el foco principal de atención con su ingeniosa creación ${ }^{79}$.

La aprobación del proyecto no obtuvo la unanimidad del cabildo, pues algún canónigo se manifestó en contra de la obra. Sabemos que Fernando Haller y Quiñones se opuso por cuestiones económicas, ya que la fábrica no disponía de liquidez, por motivos de seguridad, alegando que tanta madera podía ser peligrosa para la catedral por la posibilidad de un incendio, y también por cuestiones estéticas, siendo más partidario de un altar con mármoles y alabastro. $\mathrm{Su}$ propuesta no fue aceptada a pesar de que

${ }^{77}$ Sobre el retablo de Narciso Tomé, véase: F. ÁLVAREZ, "La pulchra leonina y su retablo de la capilla mayor", Archivos leoneses, $\mathrm{n}^{\circ}$ 12, León, 1952, pp. 95-109; J. A. Moreiro GonZÁLEZ, "El retablo de Thome en la iglesia de S. Francisco, en León", Tierras de León, n 49, León, 1982; J. M. PRADOS GARCíA, "El retablo mayor del siglo XVIII de la catedral de León”, Archivo Español de Arte, t. 55, nº 220, pp. 329-350; F. Llamazares RodRíGUEZ, El retablo barroco..., pp. 362-374; J. RIVERA BLANCO, "Narciso Tomé y los restos del Colegio Apostólico del antiguo retablo de la catedral de León", B.S.A.A., nº 43, Valladolid, 1977.

${ }^{78}$ Para el trasparente contrató una vidriera en Barcelona, A.C.L., Fondo General, doc. 10.037, s/f.:

...Y asi mismo se dio orden al señor administrador de la fabrica para que escriba al señor Rios que se alla en Barzelona, bea y ajuste si ai quien aga la bidriera para el trasparente del altar maior, y que se le remitan las medidas para eso.

${ }^{79}$ Como dice J. J. MARTín GonZÁlez, El retablo barroco,..., p. 5, "una catedral gótica puede hacerse barroca gracias a sus retablos". 
escribió un memorial al rey para impedir la realización del característico retablo barroco ${ }^{80}$.

En 1738 hizo las primeras trazas y las obras empezaron en el año $1740^{81}$, pero pronto las ocupaciones de Tomé y su cargo en Toledo le impidieron asentarse en León, por eso tuvo que nombrar hombres de confianza para la labor diaria, entre los que destacaron Alonso de la Fuente como aparejador, y Simón Gabilán Tomé como maestro ${ }^{82}$. Este arquitecto, escultor y pintor toresano llegó con su primo Narciso para realizar el retablo, quedándose al cargo de la dirección cuando éste se volvió a Toledo. Durante su estancia en León, antes de su instalación definitiva en Salamanca donde alcanzó gran reputación e importantes cargos, fue también maestro de obras de la catedral, al menos entre los años 1738 y $1744^{83}$. Contribuyó por ${ }^{80}$ Este asunto lo trata J. M. PRADOS GARCÍA, ob. cit., p.

${ }^{81}$ A.C.L., Fondo General, doc. 8.780 , fol. 7:

...escrivieron a la santa yglesia de Toledo permitiese que don Narciso Thome maestro arquitecto de ella viniese a reconocer el sitio y a acer diseño para la execuzion de nuevo retablo, lo que se consiguio con lizencia que para ello le dio a instancia de dicha santa yglesia el señor infante cardenal arzobispo de ella, cuio diseño executo dejando persona que executase y siguiese la planta, asi en lo correspondiente a madera, como en lo perteneziente a piedra, y a que se dio principio en el abril del año de mil setezientos y treynta $y$ ocho, supliendose sus primeros gastos con cinquenta mil reales que ofrecio de limosna un devoto incognito por mano del señor don Francisco Almirante, canonigo desta santa yglesia y abiendose proseguido en dicha obra y asentandose la primera piedra del pedestal de dicho retablo maior, se puso en un hueco que en ella se labro y cubrio con otra, adornada de embutidos de piedra blanca la inscripción siguiente esculpida en una plancha de plomo, que dize asi:

A la mayor onra de Dios Nuestro Señor y de su Madre Santísima, se asento la primera piedra del pedestal del retablo maior en el día seis de agosto del año de mil setecientos y quarenta, vacante la silla pontificia por muerte de la Santidad de Clemente XII, reynando la magestad catholica de nuestro monarcha don Felipe $V$, siendo obispo de este obispado el Ilmo Sr. D. Fr. Joseph de Lupia y Rojer, quien en dicho día vendijo dicha piedra, y dean desta santa yglesia el Sr. Dr. D. Miguel Geronimo Pola, y administrador de la fabrica el Sr. D. Vicente Saavedra, y maestro arquitecto D. Simon Gabilan, y se empezo dicha obra siendo administrador el Sr. D. Diego Viguera.

${ }^{82}$ A.C.L., Fondo General, doc. n ${ }^{\circ} 8.779$, fols. 88 y 98 :

... Plana del aparejador don Alonso de la Fuente

... Libramientos dados al maestro don Simon Gavilan Tome por su salario en el año de 1740

${ }^{83}$ A.H.D.L. Protocolos de Dionisio Ibáñez de la Madrid, $\mathrm{n}^{\circ} 118$, c. 86 , fol. 267 :

... ante mi el notario mayor parecio Joseph Feeyjoo ... y presento por testigo a D. Simon Gavilan Thome maestro arquitecto ... y dijo que como tal maestro arquitecto y a cuio tanto de forma decisiva en la transformación barroca de la catedral, en una labor que excedió a la retablística, como veremos a continuación ${ }^{84}$.

Una vez muerto Tomé, todavía fue necesario hacer algunas trazas para finalizar el retablo, y aquí aparece de nuevo el providencial Giacomo Pavía diseñando los últimos elementos para su conclusión definitiva ${ }^{85}$.

El retablo, que tantas críticas tuvo desde que se implantó el gusto neoclásico ${ }^{86}$, estuvo presidiendo la capilla mayor hasta que la restauración decimonónica decidió quitarlo ${ }^{87}$. En su lugar se puso otro con tablas de Maese Nicolás que se conservaban del original gótico ${ }^{88}$. Hoy se mantienen algunas partes del retablo barroco en la iglesia del convento de san Francisco de la misma ciudad, donde se colocaron tras su des-

cargo an corrido y corren todas las obras de dicha Sta. Yglesia desde el año pasado de mil setezientos y treinta y ocho asta el presente (1744)

${ }^{84}$ Así por ejemplo en febrero de 1743 fue el encargado de la obra de la capilla del Carmen que se había declarado en ruina, A.C.L., Fondo General, doc. 10.036, s/f..

${ }^{85}$ A.C.L., Fondo General, doc. n ${ }^{\circ} 10.037$, s/f:

...Papeles y trazas de el maestro don Jacobo Pavia de el arco del retablo, columna y espejuelo

${ }^{86}$ Sirva como ejemplo la cantidad de improperios que le dirigió A. PONZ en su Viage de España, t. XI, Madrid, 1784, pp. 220-222 (ed. Madrid, 1972): "Solo en el semicirculo en tornó de la capilla mayor es donde hay retablos, que si atendemos al artificio, seria mejor que algunos no los hubiese. El de la capilla mayor puede servir de norma para quantos disparates se quieran hacer en materia de arquitectura".

"Me desespera ver en las Iglesias de esta clase ornatos tan feos; y lo que mas me confunde es que hayan de estar manifestando a nuestros venideros lo poco que valió gran parte de nuestro siglo, respecto del tiempo gótico, y el gran desperdicio que se hizo de pinares, $y$ dinero para vergüenza de él. No parece (decía un Profesor) sino que para adornar este retablo se habian recogido los pellejos de todos los borregos, ovejas, y carneros, que por algunos dias se habian muerto en los contornos de Leon, convirtiendo el retablo en una pellegeria. Pellejos en el basamento, en las columnas, cornisas, capiteles, desgajándose por todo pedazos de pellejos, Ya en el Transparente de Toledo se habia introducido, entre otras, esta gentil mamarrachada, pero en el retablo de aqui subió mucho de punto".

${ }^{87}$ D. DE LOS Ríos, ob. cit., p. 182, se vanagloria de haber sido quien desmanteló el retablo: Simón Tomé Gavilán. Este, no diremos tramoyista como le llama Cean Bermudez, ejecutó el retablo mayor que nosotros hemos tenido la satisfaccón de quitar del ábside.

${ }^{88}$ En el cabildo de 28 de agosto de 1880 se decidió quitar el retablo y cederlo al convento de S. Francisco de la misma ciudad, donde, desmembrado y mutilado continúa, sin poder desarrollar todas sus posibilidades. Sobre el desmantelamiento véase A.C.L., Fondo General, doc. 10.063, $\mathrm{s} / \mathrm{f}$. 
mantelamiento. La apariencia total de la obra barroca la conocemos gracias a un cuadro que se conserva en el convento de las Clarisas de Villalpando (lám. 3).

Para albergar la magnitud que deseaba dar Tomé a su obra no era suficiente la superficie libre del presbiterio que había en su momento ${ }^{89}$. Era imprescindible ampliar el espacio disponible con el fin de que el gran artefacto que proyectaba para enriquecer la cabecera de la iglesia tuviera pleno desarrollo y pudiera resultar acorde con las ideas que estaban en la imaginación del maestro y las pretensiones que quería lograr el cabildo, que estaba preocupado por su comodidad en los oficios religiosos, deseoso de adaptar el templo a los nuevos valores de la liturgia y continuar con la transformación estética de la catedral. Por todas estas razones era inevitable desplazar el coro, una obra monumental que contaba con un artístico cierre pétreo del renacimiento de gran riqueza escultórica ${ }^{90}$. Ubicado en la cabecera del templo, delante del altar, cerraba de esta manera la capilla mayor, mientras que el órgano estaba separado de ésta y de la nave central por sendas rejas ${ }^{91}$. Se reabría así un polémico proceso sobre la conveniencia de trasladar el coro al centro del templo en el que intervinieron diversos intereses ${ }^{92}$. La cues-

${ }^{89}$ En su momento se llegó a votar en cabildo si se trasladaba el coro o no, pero con la premisa de que el retablo se iba a hacer igual, ACL, Fondo General, doc. 10.034, fols. 9 v. y $10 \mathrm{r}$.:

...I aviendo dicho los demas señores, cada uno segun su antigüedad, el dictamen que en este asunto avia formado, sin embargo de todo lo referido, se puso nombre a las habas y se prozedio a votar, declarando el señor primiziero haba blanca que se haga el retablo mudando el choro, haba negra que se haga el retablo quedandose el choro como esta ... I aviendo acabado de votar segun el orden del cavildo, $i$ reguladas las habas, salio haba blanca por mayor numero de habas, y por consiguiente fue visto acordar que se haga el retablo mudando el choro.

${ }^{90}$ Sobre la historia constructiva del coro y su estudio artístico, véase: M. D. CAMPOS SÁNCHEZ-BORDONA, "Las transformaciones..., pp. 168-181; ÍDEM, Juan de Badajoz y la arquitectura del Renacimiento en León, León, 1993, pp. 376-397; J. RIVERA BlANCO, Arquitectura de la segunda mitad del siglo XVI en León, León, 1982, pp. 70-73; M. D. CAMPOS, M. D. TEIJEIRA E I. GONZÁLEZ-VARAS, El coro de la catedral de León. Arte, función y símbolo, León, 2000.

${ }^{91}$ P. NAVASCUÉS PALACIO, "El coro y la arquitectura de la catedral. El caso de León", Medievalismo y neomedievalismo en la arquitectura española: Las catedrales de Castilla y León, Avila, 1994, p. 53, considera que la cabecera de la catedral leonesa fue diseñada precisamente teniendo en cuenta esta disposición del coro.

92 No nos detenemos en el proceso de traslado del coro porque ha sido suficientemente estudiado, además nuestro tión ya había tenido sus prolegómenos en el siglo XVI, aunque entonces se optó por dejarlo en su primitivo sitio $^{93}$.

El coro, como un espacio autónomo dentro del templo, está reservado a los canónigos y tiene una función litúrgica bien definida, por lo que necesita estar separado del espacio destinado a los fieles ${ }^{94}$. En León, su ubicación original y el cerramiento artístico del trascoro, dificultaba el seguimiento de los actos litúrgicos por parte de los fieles, que apenas podían ver el altar, en clara contradicción con la doctrina tridentina que preconizaba la participación de los fieles en los oficios religiosos ${ }^{95}$. Por esta razón pronto se pensó en mudar el coro a la nave mayor ${ }^{96}$. El primer intento de traslado a la nave central se remonta a 1560 , pero no se aprobó definitivamente hasta 1737 durante el obispado de Lupiá Roger ${ }^{97}$, iniciándose efecti-

interés está más en la nueva significación del espacio que en el procedimiento seguido. Véase M. D. TEIJEIRA PABLos, "La sillería gótica de la catedral de León: hipótesis sobre su disposición original", Anales de la Historia del Arte, $\mathrm{n}^{\circ} 4$, Madrid, 1994, pp. 513-521; ÍDEM, "El traslado de la sillería coral de la catedral de León en el siglo XVIII. La aportación documental", Estudios Humanisticos, n 16, León, 1994, pp. 233-241; ÍDEM, "Los intentos de traslado y la ubicación definitiva del recinto coral durante el siglo XVIII" en El coro de la catedral de León, pp 141-145; P. NAVASCUÉS PALACIO, "El coro y la arquitectura...

${ }^{93}$ En el proceso llegó a intervenir el rey Felipe II, véase, Archivo Histórico Municipal de León, leg. 19. El documento lo transcribe R. Álvarez DE LA BRAÑA, "Provisión del rey Don Felipe II para que no se haga coro en medio de la catedral de León", Revista de Archivos, Bibliotecas y Museos, t. III, 1899, p. 115.

Otros intentos se recogen en A.C.L., Cajón Roma Choro, letra C, leg. 37, $\mathrm{n}^{\circ}$ 584. Doc. 8.785:

Ynivicion a favor desta Santa Yglesia. Contra la pretension del Sr. Obispo sobre mudar el choro y distribuzion de los vienes de la fabrica contra lo ejecutoriado en la concordia:

A.C.L., Fondo General, doc. 8.786: Suplicas, representaziones, memoriales y apuntamientos hechos para representar a Su Santidad el ynconbeniente de mudar el choro y que el señor obispo no pueda por si distribuyr los bienes de la fabrica contra lo executoriado en la concordia.

${ }^{94}$ Sobre el significado del coro en las catedrales españolas, véase, P. NAVASCUÉs PALACIO, Teoría del coro en las catedrales españolas, Madrid, 1998; M. D. CAMPOS SÁNCHEZ BORDONA, "La delimitación del espacio coral como símbolo de la jerarquización eclesiástica del interior del templo", en El coro de la catedral de León, León, 2000, pp 105-131.

95 A. Rodríguez G. DE CEBALlos, "Liturgia y configuración ..., pp. 43-52.

${ }^{96}$ P. NAVASCUÉS PALACIO, "El coro y ..., p. 74, apunta la hipótesis de que el pensamiento erasmista pudiera estar detrás de las primeras renovaciones de los coros.

97 A.C.L., Fondo General, doc. 10.034 , fols. 9 v. y 10 r: 
vamente en 1742, con motivo de la realización del citado retablo ${ }^{98}$. El cambio se decidió sin la unanimidad de los capitulares, alguno de los cuales eran muy reacios a las novedades. Al final prevaleció la opinión de Narciso Tomé, quien argumentaba que liberando espacio en el presbiterio, la catedral quedaría mejor dispuesta para el lucimiento y solemnidad de las ceremonias litúrgicas propias de la época, donde era tan importante el boato y la solemnidad del rito. Además de aumentar la belleza del conjunto, introduciendo un elemento novedoso, la catedral ganaría un aire más moderno y perdería parte de su apariencia medieval. Sin duda Tomé quería dar el mayor protagonismo posible al retablo, considerándolo el elemento esencial de la transformación de la catedral ${ }^{99}$. Por esta razón quería tener el máximo espacio disponible para desarrollar en toda su amplitud y con total libertad su capacidad creadora ${ }^{100}$.

\section{-}

...I aviendo acabado de votar segun el orden del cavildo, $i$ reguladas las habas, salio haba blanca por mayor numero de habas, y por consiguiente fue visto acordar que se haga el retablo mudando el choro. Y en consequencia de esto se acordo el que se de parte de esta determinazion al señor obispo nuestro prelado i que el maestro haga diseño del retablo

${ }^{98}$ A.C.L, Fondo General, doc. 10.036, s/f.

${ }^{99}$ En el siglo siguiente hubo intentos de devolver el coro a su primitiva ubicación. Juan de Madrazo y algunos restauradores posteriores de la catedral como Demetrio de los Ríos y Juan Bautista Lázaro, eran de esa opinión. Sobre este tema véase: I. GONZÁLEZ-VARAS IBÁÑEZ, La catedral de León..., pp.404-422; también, P. NAVASCuÉs PALACIO, "El coro y la arquitectura...", pp.84-94.

${ }^{100}$ A.C.L., Fondo General, doc. no 8.780, fols. 3-6 r:

Ilmo. Sr., abiendo benido de horden de V. S. Ilma. a reconocer el sitio del retablo que V. S. Ilma. yntenta azer en la capilla mayor desta santa yglesia, y bisto con toda reflexion y cuidado el modo y disposicion que puede tener para su mayor luzimiento soi de sentir que para conseguirle y delinear un retablo correspondiente a la grandeza y grabedad de esta santa yglesia es nezesario en primer lugar mudar el coro desde el cruzero (dejandole libre) en el cuerpo de la nabe prinzipal, pues deste modo se consiguen entre otras cosas dos prinzipalisimas, la una el mayor luzimiento del retablo y dejar la capilla mayor con todo desaogo aziendo presbiterio mui capaz para todas las funziones que V. S. Ilma. tiene, y la otra, para dichas funciones la grabedad y seriedad con que V. S. Ilma. las puede zelebrar pasando desde el coro a la capilla mayor sin estorbo de jentes que enbarazen el paso poniendo para este fin, barandas desde el coro a la capilla mayor como usan todas las yglesias, logrando de esta forma todo el pueblo ber los ofizios dibinos lo que oi por la estrechez del sitio no puede lograr ni tener luzimiento las funciones principales $=$ $Y$ si V. S. Ilma. no determinase mudar el coro como llebo dicho por ynconbenientes que tenga que yo no alcanzo, se podra debajo de la disposicion que oi tiene delinear retablo bueno, mas con tal limitacion que no pueda la fantasia y
El deseo de innovación se impuso y la propuesta del maestro fue finalmente aceptada, lo cual supuso toda una revolución en el edificio, pues fue necesario realizar una serie de obras con el fin de reorganizar la cabecera del templo (lám. 5). Al retirar el coro de su primitivo lugar se produjo una dislocación del espacio, haciendo necesaria una adecuación de la novedosa disposición resultante para que pudiera cumplir con las diversas funciones religiosas que se sucedían en un templo catedralicio del barroco. Al mismo tiempo, algunos elementos del edificio quedaron dañados por la obra, y fue necesario diseñar su restauración. La circunstancia fue aprovechada para hacer nuevas estructuras arquitectónicas en el cerramiento del coro, colocar nuevo mobiliario en la nave central, demarcar la vía sacra, renovar la solería del presbiterio, sin descartar que se pintaran algunos muros o pilares, según se desprende de un informe de 1746 en el que se habla de ...acabar de dar blanqueo y color a la yglesia ${ }^{101}$. El encargado de dirigir toda esta obra fue el citado Simón Gabilán Tomé, contando con la ayuda como primer oficial aparejador del trasmerano Fernando de Compostizo, quien más tarde sería maestro de obras de la catedral ${ }^{102}$.

Para colocar el coro en su nueva disposición era indispensable, en primer lugar, alargar los muros laterales, pues la fábrica renacentista no llegaba a cerrar la sillería en toda su exten$\operatorname{sió}^{103}$. De esta manera, se amplió un tramo más en cada costado, con un diseño que marca una

trabesura del arte ejerzer la ydea extraordinaria que puede ocurrir, por la escasez del sitio pues sienpre la ydea se allara cortada sin poder esplayarse por no poder cojer planta sobre que fundarla, y aunque se logre medianamente (que no podra ser superior) a de tener poco luzimiento por no tener sitio con desaogo por donde se pueda rejistrar a un tienpo todo el retablo pues por las rejas de los lados solo se podra ber la mitad y por la del trascoro, con el estorbo de fazistoles suzedera lo mismo el no poder gozarle, y respecto de lo que llebo referido y parezerme grabes ynconbenientes estos, pues no se podra conseguir el mayor luzimiento

101 A.H.D.L., Protocolos de Dionisio Ibáñez de la Madrid, $\mathrm{n}^{\circ} 119$, c. 87 , fol. 119 .

102 A.C.L., Fondo General, doc. 10.036, s/f.:

...que Gabilan maestro del retablo corra como maestro prinzipal y de primer ofizial y asentista, Compostizo.

103 J. RIVAS CARMONA, Los trascoros de las catedrales españolas: estudio de una tipología arquitectónica, Murcia, 1994 , p. 16, precisa como los coros tienen un cerramiento que los individualiza y separa del resto del conjunto, con unos muros exteriores tratados como si verdaderamente fueran las fachadas de un edificio, realizados en piedra ya que se trata de una edificación más del templo, no de un simple adorno. 
clara diferencia morfológica con la fábrica renacentista (lám. 6). A la hora de hacerlo se tuvo cuidado de que no fuera un mero cerramiento sin más, sino que se quería lograr una obra de categoría artística, aunque no de mucho coste, para mayor lucimiento de la catedral ${ }^{104}$. Esta ampliación se ha atribuido a Simón Gabilán Tomé, seguramente porque por aquellas fechas era el maestro de obras de la catedral ${ }^{105}$, pero realmente no se tiene datos documentales ciertos sobre la autoría de la traza.

Los nuevos muros se trazaron rompiendo formalmente con la obra renacentista precedente, imponiendo una morfología y un léxico propio del barroco, sin atender a la unidad de estilo en una misma obra, de manera que la continuidad lineal de las paredes laterales resulta dividida en dos paños de apariencia diferente, e incluso contradictoria. Pero, eso sí, resaltando la utilización de un lenguaje arquitectónico moderno.

El trascoro renacentista tenía un gran vano con arco de medio punto en su parte central, con el objetivo de que los fieles pudieran ver el altar a través de él. En la nueva ubicación la apertura perdía su razón de ser, ya que el altar quedaba muy lejos y lo que en realidad quedaba a la vista era el espacio coral privado, por eso los capitulares decidieron cerrarlo de la manera más sencilla, con unas grandes puertas de madera, según se puede ver en fotografías antiguas ${ }^{106}$. De esta manera el trascoro quedaba opaco con lo que se conseguía esquivar las miradas desde el exterior cuando el cabildo estaba en sus funciones, y por otro lado se evitaba el frío que entraba por esa abertura, algo que preocupaba especialmente a los canónigos leoneses ${ }^{107}$ (lám. 7).

-

104 ACL, Fondo General, doc. 10.036, s/f.:

... propuso el Sr. Thesorero; como en el choro que aora se fabrica seria conbeniente que en sus costados se diese alguna labor, como arco sepulcro o otra labor, que no siendo de mucha costa fuese de luzimiento de la obra; lo que se acordo y que fuese a la prudencia del maestro.

105 J. RIVERA BLANCO, Arquitectura de la segunda..., p. 72, nota 61; ÍDEM, Historia de las restauraciones..., p. 145; También M. D. CAMPOS Y OTROS, El coro..., p. 130.

${ }^{106}$ Fueron sustituidas por una mampara de cristal, como está hoy en día, al cambiar sustancialmente en la actualidad la consideración del espacio catedralicio

${ }^{107}$ Así lo recoge A. CABEZA, La vida en una catedral del Antiguo Régimen, Palencia, 1997, p. 32. También estaba previsto el cierre de las demás puertas, cfr. ACL, Fondo General 1740-1744, doc.10.036, s.f.: ... Dijo el señor procu-
Como consecuencia del traslado se plantearon una serie de obras en el presbiterio para ayudar al retablo en el cambio de fisonomía de esta parte del templo ${ }^{108}$. Una de ellas tenía que solucionar el hueco que ahora quedaba libre en los intercolumnios de la girola al quitar los cierres antiguos, pues al suprimir las pantallas que mantenían aislado al presbiterio era necesario proyectar un nuevo cierre, como ya lo preveía Tomé en uno de sus informes ${ }^{109}$. En sesión capitular de marzo de 1746 se decidió colocar unas rejas en los laterales de la capilla mayor, ancladas sobre unos nuevos pedestales de mármol con decoración de placas recortadas y varios colores (lám. 8) ${ }^{110}$, realizando al mismo

rador como la Junta abia notado que las puertas que los corillos tienen a sus costados para el uso del choro sobre ser dorno su cierro, parecia conocido abrigo y resguardo del frio, maxime cuando su uso se condeno en el choro antiguo.

108 A.H.D.L. Protocolos de Dionisio Ibañez de la Madrid, $\mathrm{n}^{\circ} 118$, c. 86 , fols. 267 y ss.:

...D. Simon Gavilan Thome maestro arquitecto ... y dijo que como tal maestro arquitecto y a cuio cargo an corrido y corren todas las obras de dicha Sta. Yglesia ...es preziso con yndispensable nezesidad continuar las obras que tiene $y$ estan pendientes ...que son en primer lugar los enlosados de la capilla mayor, presviterio y paso de la entreballa al coro, los zocalos de la rejeria, las gradas de la capilla mayor, los pulpitos conforme a la planta echa por el testigo y aprobada por los señores Dean y Cavildo, los adornos que faltan al pedestal y concluirle enteramente los colaterales a correspondencia de el retablo, las puertas de el trascoro, la rejeria del coro, capilla mayor, valla y puertas para la entrada a dicha capilla, el espejuelo que esta amenazando ruina enzima de la puerta de san Froylan, el machon apoyado y las vovedas que cargan sobre el, con la reficion de sus quiebras, un organo con su caja, todo correspondiente a lo sumptuoso de el templo, la media naranja enzima de el cruzero que es obra sumamente prezisa y de excesibo costo, como lo es asi mismo la reficion de el claustro y sus tejados, la de la capilla del dado, torre de las campanas y socalzos de toda la yglesia....

109 A.C.L., Fondo General, doc. 8.780, fol. 8:

... rejas que se nezesitan mudando dicho coro son las dos prinzipales, de capilla mayor con pulpitos, y la del coro, $y$ asi estas como las de los quatro claros que quedan en la capilla mayor y baranda desta capilla al coro, me parece podra importar todo con su zocalo y basa de piedra, el importe de seis a siete mi lducados, teniendo dichas rejas su coronación correspondiente...

110 A.C.L., Fondo General, doc. n ${ }^{\circ} 10.037$, s/f.:

Parecer de diputacion sobre que se tomen las quentas de la fabrica y a bista de los alcances ber si es combeniente azer las rexas de la capilla maior y coro

...si combendria azer las rexas prinzipales de la capilla maior y las del coro fueron de parecer que si al cabildo le pareziere podra acordar que atendiendo al estado de la capilla maior que esta zerrada por los lados, se tome probidenzia de que se agan quanto antes las correspondientes a la fachada de dicha capilla maior y coro siendo la primera segun el modelo del maestro Pabia y la del coro lisa y baxa 
tiempo las correspondientes a la fachada de la capilla mayor y coro, siendo la primera según el modelo diseñado por el polifacético Pavía, y la del coro lisa y baja para que quedase la capilla adornada y cerrada al mismo tiempo ${ }^{111}$. Se estableció así la vía sacra que unía el coro con la capilla mayor, también cerrada y delimitada por una reja que separaba a los fieles de los eclesiás$\operatorname{ticos}^{112}$.

Con la nueva ordenación espacial había que colocar los púlpitos en un sitio más apropiado, pues no podemos olvidar los valores y la importancia decisiva que tenía la predicación para la época barroca. En reunión capitular de enero de 1750 se decidió que el mejor lugar para situarlos era al lado del coro ${ }^{113}$, según criterio del maestro de ceremonias, de manera que quedaban en mitad del templo y por lo tanto muy cercanos a los fieles para que oyeran sin dificultad la palabra divina y los sermones, tan útiles para el adoctrinamiento del pueblo ${ }^{114}$. La ocasión se aprovechó para hacerlos al gusto de la época, según un proyecto elaborado en 1746 por el tantas veces citado maestro Giacomo Pavía, asimismo también encargado de hacer la traza del altar $^{115}$. Los púlpitos, a modo de grandes

para que de esa suerte quede la capilla adornada y zerrada la iglesia en esta parte con uniformidad

${ }^{111}$ Los rejeros que probablemente trabajaron en ellas fueron Juan Morales, Froilán Gutiérrez, Francisco Fernández Cancelo, Pedro Álvarez, Juan Gómez y Pedro Díez, ya que eran los que estaban trabajando en la catedral en el año 1744, véase D. DE LOS Ríos, ob. cit., p. 213.

${ }^{112} \mathrm{Al}$ respecto conviene recordar la definición de vía sacra como una especie de iglesia clerical dentro de la catedral, de la que estaban excluidos los fieles, que propone A. RODRÍGUEZ G. DE CEBALlOS, "Liturgia y configuración del espacio en la arquitectura española y portuguesa a raíz del Concilio de Trento", Anuario del Departamento de Historia y Teoría del Arte, 1991, pp. 43-52.

${ }^{113}$ Fueron colocados adosados a los pilares delanteros del crucero, según se ve en el grabado de Sánchez Pretejo (lám.1) y en el de Parcerisa publicado en el libro de J. M. QUADRADO, op. cit, p. 328, pero al parecer en la reforma decimonónica se trasladaron a los pilares traseros del crucero, donde están ahora.

114 A.C.L., Fondo General, doc.10.038, s.f.:

...Sobre mudar el pulpito para oir los sermones, en bista de los informes de los señores maestro de zeremonias y prebendados de ofizio, y no obstante lo acordado en el dia treinta de diziembre, abiendo ablado cada señor en su lugar sobre ello, se acordo que el pulpito nuebo se mude y se ponga junto al coro, que es el sitio que an aliado mas a proposito los señores maestro de zeremonias y prebendados de ofizio

115 A.C.L., Fondo General, doc. n ${ }^{\circ} 10.037$, s/f:

Parezer de diputacion sobre los modelos de pulpitos $y$ altar maior. copas de mármol, fueron realizados utilizando una buena labor de incrustación, con diseño de clara influencia italiana y marcada policromía gracias a la combinación de piedras de varios colores $^{116}$, mientras que los tornavoces son de madera policromada y dorada, con iconografía evangélica en la coronación donde aparece el tetramorfos entre angelotes, y una profusa decoración propia del final del barroco español recubriendo toda su superficie ${ }^{117}$ (lám. 9 y 10).

El levantamiento del coro hizo necesario igualmente enlosar de nuevo la capilla mayor y el presbiterio, así como elevar unas gradas para hacer más visible el altar desde la distancia ${ }^{118}$. Con el fin de lograr un destacado carácter exornativo y otorgar mayor apariencia de suntuosidad a la zona culminante del templo, se optó por utilizar en su construcción jaspes de colores combinados con losas negras, formando un dibujo geométrico sencillo pero efectivo ${ }^{119}$. No

Otro parezer sobre los modelos, cometiose a diputación con asistenzia del señor administrador de la fabrica ber si sera combeniente hazer modelos de pulpitos y de mesa de altar maior segun los que deliniase el maestro Pabia sin que este espere a que los ofiziales les agan de piedra por ser nezesario para esto detenerse mucho mas tiempo, fueron de parezer que si al cabildo pareziese podia acordar que se aga un pulpito de buena madera que sirba de modelo a los que de piedra se an de trabajar segun el diseño dado por el maestro Pabia, y eso sin colunas por el gasto eszesibo, el qual modelo de madera serbira despues en la yglesia para las oposiziones y otras funziones. $Y$ en quanto al altar maior, atendiendo la diputacion que las piedras de este pais son de baxo color y calidad, y el sumo costo, segun lo que tiene trazado el maestro Pabia, es de sentir que se aga solo un altar dezente que deba llebar los frontales correspondientes a las festibidades y en esta ydea debera el cabildo dar contraorden para que no se saquen ni se traiga mas piedra de marmol blanco ni agatado que la que fueren prezisa para los pulpitos.

${ }^{116}$ Estos púlpitos influyeron sobre los que se hicieron poco tiempo después para el convento de S. Marcos, véase, E. Morais VAllejo, "El cancel de la iglesia de San Marcos de León”, Estudios Humanísticos, no 21, León, 1999, pp. 219-235.

${ }^{117}$ Los tornavoces de los púlpitos fueron dorados en 1770 por el maestro Manuel García, quien también doró diez florones de las bóvedas, según recoge R. RODRÍGUEZ, "Anotaciones leonesas. Recopilación de Filemón de la Cuesta", Studium legionense, 1970, n 11, p. 183.

118 A.H.D.L. Protocolos de Dionisio Ibañez de la Madrid, $\mathrm{n}^{\circ} 118$, c. 86 , fols. 267 y ss.

...las mas urgentes e yndispensables sin las quales no se puede bolber el Cavildo al coro son los enlosados de la capilla mayor, con los zocalos de la rejeria y gradas de la entrada de dicha capilla...

${ }^{119}$ Conocemos algunos apuntes contables de los materiales utilizados, provenientes de las canteras de Boñar y Llanos de Alba. A.C.L., Fondo General, doc. 9.678, fol. 133: 
sabemos hasta que punto la restauración de Torbado alteró esta parte (lám, 11).

Otra idea que se llevó a la práctica, derivada del traslado del coro, fue hacer un nuevo órgano, con el deseo de alcanzar todas las posibilidades que ofrecía este instrumento para la liturgia, después de las transformaciones operadas en el arte musical desde finales del siglo XVI y que alcanzaron su pleno desarrollo en el barroco $^{120}$. Para esto no servía el antiguo instrumento ubicado en el presbiterio, haciéndose necesario encargar otro con mayores registros, pero también de aspecto más artístico. El acuerdo se tomó en mayo de 1744 como una parte más de la reestructuración que se estaba haciendo en el interior de la catedral ${ }^{121}$. En septiembre del mismo año se aprobó el proyecto para realizarlo, teniendo como modelo el que disponía por entonces la catedral de Oviedo ${ }^{122}$, aunque dos años después todavía no estaba termina$\mathrm{do}^{123}$. Los artífices que recibieron formalmente el encargo fueron Pedro Echevarría, maestro organero de la catedral de Salamanca, y Luis González, que se ocupó de la caja ${ }^{124}$. El órgano se utilizó también como ornato del espacio

Las losas para el pavimento de la capilla mayor en quanto al pulimento se ajustaron con Domingo Gonzalez $y$ Bartolome Ramiro y Vizente Valboa a dos reales cada una.

... en 13 de marzo de 1745 libre treszientos y seis reales de vellon de 187 losas a 20 mrs. y 28 negras a 7 reales que travajo el cantero Moreyra y su compañero.

En 20 de marzo de 1745 libre 26 reales y 28 mrs. de 38 losas a 24 mrs. cada una. 44 rs y 24 mrs. de 38 negras a 40 mrs. y 42 rs. de labrar 6 negras a Benito y compañeros

En 3 de abril libre de 40 losas de Voñar a 40 mrs.

${ }^{120}$ Sobre la relación entre la catedral y la música véase, J. M. ÁlvAREZ PÉREZ, La música sacra al servicio de la catedral de León, León, 1995; ÍDEM, "La polifonía sagrada y sus maestros en la catedral de León”,

121 A.C.L. Fondo General, doc.10.036, s.f.:

... Cometiose a los señores de la Junta la disposizion de un nuebo organo en atencion a estar abanzada la obra del retablo, capilla mayor y choro.

122 A.C.L., Fondo General, doc. 10.037, s/f.:

123 A.H.D.L. Protocolos de Dionisio Ibáñez de la Madrid, $\mathrm{n}^{\circ} 119$, c. 87 , fols. 119 y ss.: nuevo

..concluir el organo prinzipal que se esta favricando de

124 A.C.L.,Fondo General, no 9.678, fols. 148 y 150:

... Cuenta con Luis Gonzalez, maestro que esta travajando en Salamanca la caja del organo.

El día 22 de mayo de 1745 entro en esta ciudad a las 3 de la tarde Don Pedro Chavarria maestro organero para la fabrica del organo..

... en 3 de octubre de 1745 entregue a dicho Don Pedro ochocientos rs. vellon de el archivo y son los que en el se contaron demas quando se acabo de pagar a Luis Fernandez maestro de la caja de el organo coral, por lo que se completó con buenas tallas de tamaño bastante superior al natural, realizadas en madera y policromadas con gusto rococó, que despliegan una clara intención teatral, siguiendo las tendencias de la época barroca de mezclar escultura y música ${ }^{125}$. Representan a Santa Cecilia tocando el órgano, acompañada de tres mujeres como alegorías de los valores musicales. La Mesura y la Armonía portan sendas cartelas identificativas, mientras que el Ritmo está representado por una joven bailando (lám. 12). Las esculturas femeninas, obra del afamado escultor Alejandro Carnicero, se acompañaban de una serie de ángeles con el fin de aportar mayor efecto escenográfico ${ }^{126}$. Tanto el instrumento como su adorno escultórico, que formaban en conjunto un aparatoso artefacto que ocultaba parte del triforio y subía hasta la altura de las ventanas superiores, se colocaron en el lado del evangelio, según se vislumbra en el grabado que Parcerisa hizo del interior de la catedral $^{127}$.

\section{CONCLUSIÓN.}

El principio utilizado para las actuaciones llevadas a cabo en el interior de la catedral de León durante el barroco, fue el de la apuesta audaz por la modernidad que suponía el nuevo lenguaje de la época. Cuando se ultimaron todas las empresas descritas, la intervención había metamorfoseado el espacio interior de la catedral. Superponiendo sobre la arquitectura y los códigos medievales las obras modernas, se había conseguido hacer un interior de significación barroca, útil para la liturgia del momento, conforme a los intereses del cabildo y acorde con la estética de la época. No cabe duda de que la fisonomía lograda era muy diferente a la primitiva concebida durante la Edad Media, y también distinta a la que presenta en la actualidad.

125 Las tallas fueron retiradas de su lugar durante la restauración del siglo XIX, y ahora se conservan en dependencias del Museo de la Catedral de León.

126 J. Rivera BLANCO, "Alejandro Carnicero y el órgano de la Catedral de León”, BSAA, Valladolid, 1978, n 44, pp. 485-490; ÍDEM, Las Edades del Hombre. La música en la iglesia de Castilla y León, León, 1991, pp 308-309. Sobre Alejandro Carnicero véase, J. J. MARTín GONZÁLEZ, Escultura barroca en España, Madrid, 1983, pp. 436- 444; R. LÓPEZ BORREGO, "Aportaciones a la vida y obra de Alejandro Carnicero”, BSAA, 1997, n 63, pp. 427-440.

127 J. M. QUADRADO, op. cit., p. 328. 
El espacio longitudinal gótico se fraccionó mediante el obstáculo que supuso la nueva ubicación del coro, impidiendo la visión directa del altar desde la entrada al templo, así como el camino directo de los fieles hasta la capilla mayor, que han de dar un rodeo para salvar el recinto reservado al cabildo. El espacio vertical se prolongó en altura y ganó grandiosidad gracias a la cúpula de Naveda, que ofrecía un nuevo sentido ascensional al espacio del crucero. El retablo de Tomé, con su aparatosa maquinaria decorativa, cambió el significado del presbiterio dándole singulares valores, a lo que ayudaron las nuevas rejas, los decorativos púlpitos, o el mármol polícromo de suelo, gradas y altar. Con todo ello se lograba un gran efecto de sorpresa, tan querido por el barroco, al tiempo que se aseguraba la preparación necesaria para conseguir la persuasión del fiel.

En todo momento hubo una manifiesta actitud de ruptura con el pasado, considerando caducas las formas medievales y adoptando el lenguaje propio del barroco como una novedad, vinculado al contexto social, religioso y cultural del momento.

El cabildo, sin duda, fue quien decidió el cambio, pero este tomó un rumbo concreto gracias a la pléyade de maestros que intervinieron para dar satisfacción a los deseos de los capitulares. Los numerosos arquitectos venidos de fuera -entre los que debemos destacar a Giacomo Pavía por la variedad de sus propuestas y por la serie de decisiones finales que adaptó para lograr la configuración barroca final, de fuerte carácter escenográfico-, llegados desde lugares muy diversos y con distintos cargos pero siempre de prestigio, ponen de manifiesto que había una idea generalizada y muy extendida entre la profesión sobre lo que debía ser una catedral de la Edad Moderna, ya que no se encuentran disensiones ni posturas encontradas a pesar de la multiplicidad de informes emitidos y la heterogeneidad de su procedencia; las discrepancias sólo se dan en relación con los problemas técnicos, no con las cuestiones estéticas. Así es como la sede leonesa, más que un caso particular, se puede considerar como un prototipo de la respuesta que quería dar el barroco para las catedrales de su época.

Por último, queremos subrayar que la restauración historicista del siglo XIX solucionó los eternos problemas estructurales del edificio, pero a cambio del enorme costo de eliminar los vestigios que las distintas etapas históricas habían ido dejando en la catedral leonesa, todo con el fin de llevar a cabo una restauración historicista que devolviera la pretendida forma prístina del edificio medieval. 


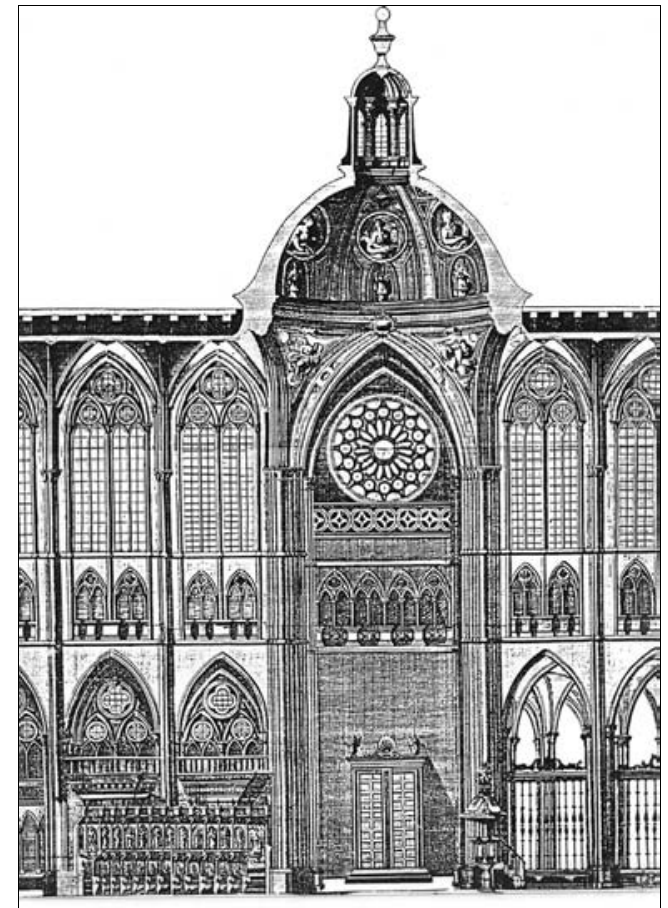

- Lám. 1. Interior de la catedral de León con la cúpula de Naveda y la linterna diseñada por G. Pavía. Dibujo de Fernando Sánchez Pertejo publicado en M. Risco, Iglesia de León y monasterios antiguos y modernos de la misma ciudad, Madrid, 1792.

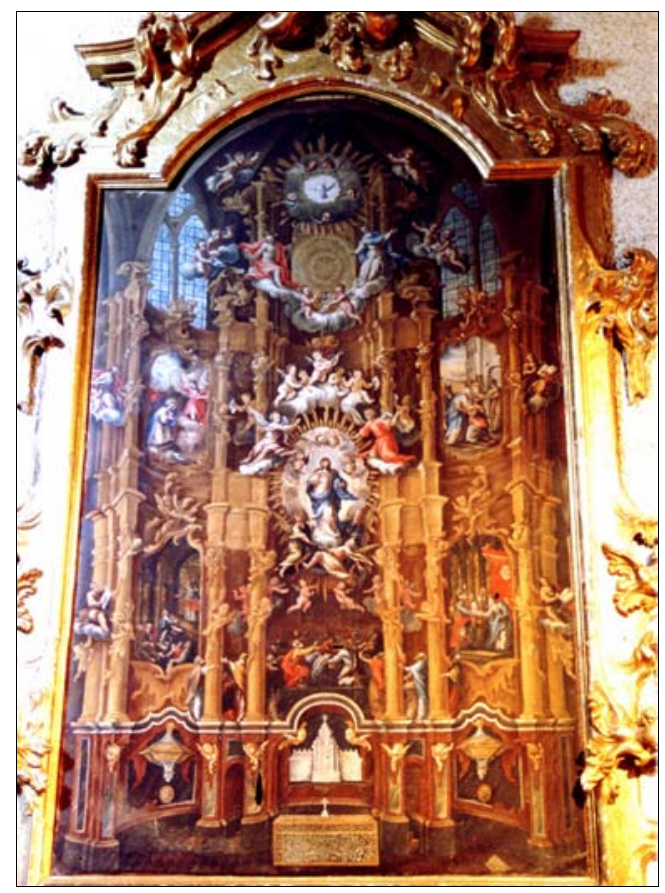

- Lám. 3. Cuadro que representa el retablo de N. Tomé completo, en su ubicación original de la catedral. Convento de las Clarisas de Villalpando. (Foto del autor)

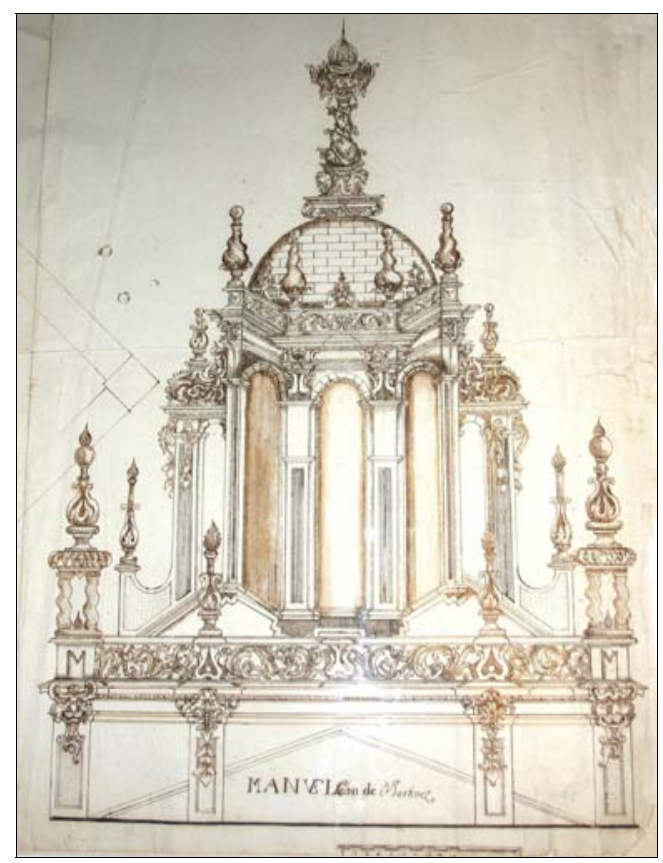

- Lám. 2. Traza de M. Conde Martínez para la linterna de la cúpula. Archivo de la Catedral de León, pasillo alto, $\mathrm{n}^{\circ} 28$.

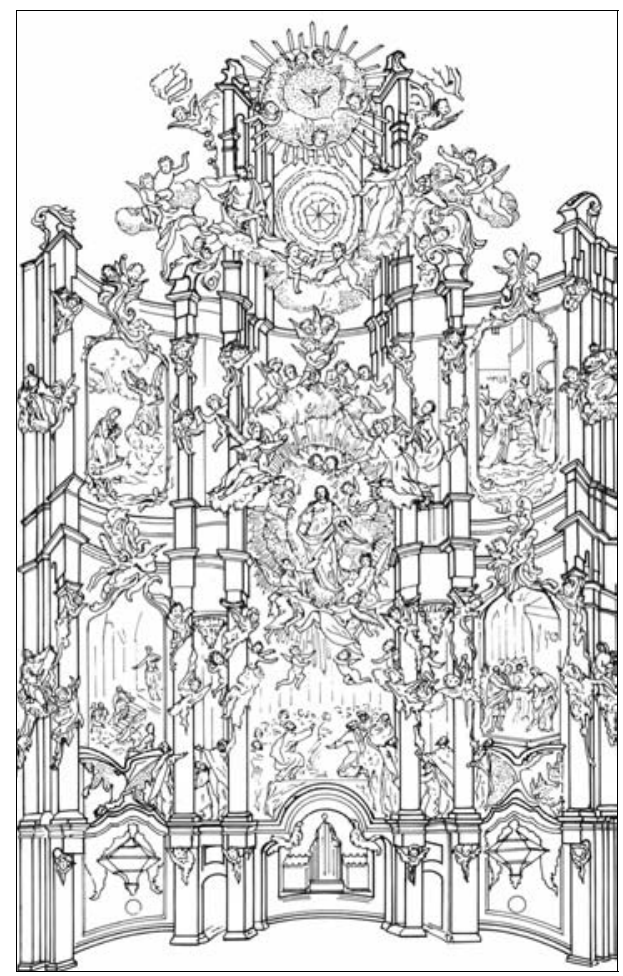

- Lám. 4. Dibujo del retablo mayor de la catedral de R. M. Martín y J. Sancho, publicado por J. J. Martín Glez., El retablo barroco en España, Madrid, 1993. 


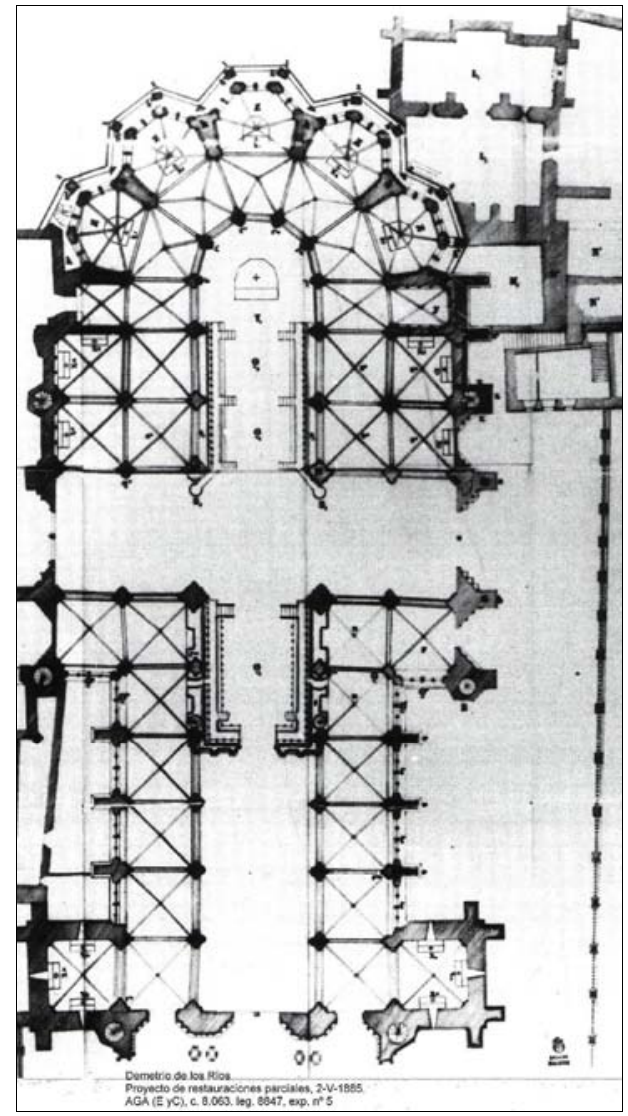

- Lám. 5. Planta de la Catedral de León realizada por Demetrio de los Ríos en la que figura el coro en sus dos ubicaciones, la primitiva y la actual. (Archivo General de la Administración del Estado, sección Educación y Ciencia, c. 8.083, leg. 8.847, exp. $n^{\circ} 5$ ).

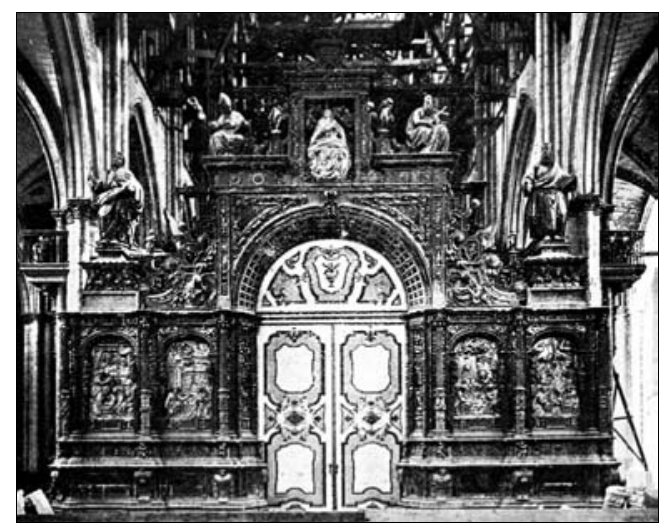

- Lám. 7. Trascoro de la catedral de León con las puertas originales que lo cerraban. (Archivo fotográfico del Instituto Leonés de Cultura).

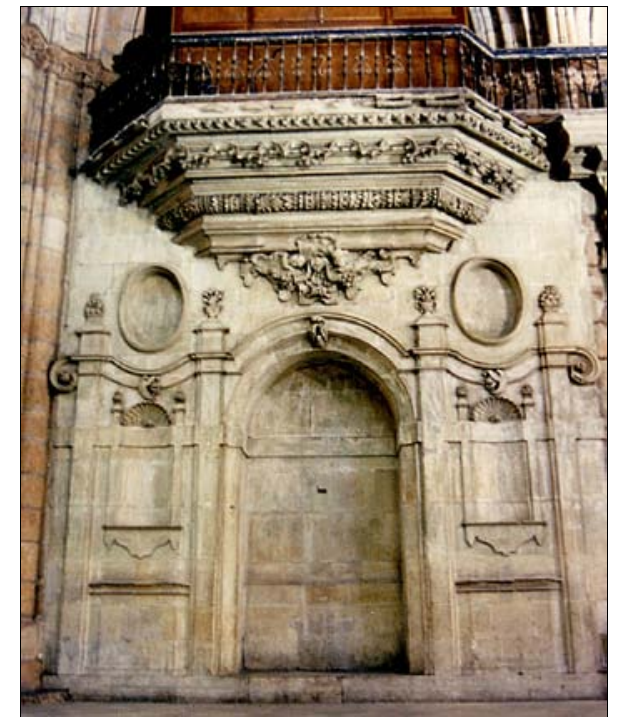

- Lám. 6. Detalle de la ampliación lateral del coro, realizada durante el barroco. (Foto del autor).

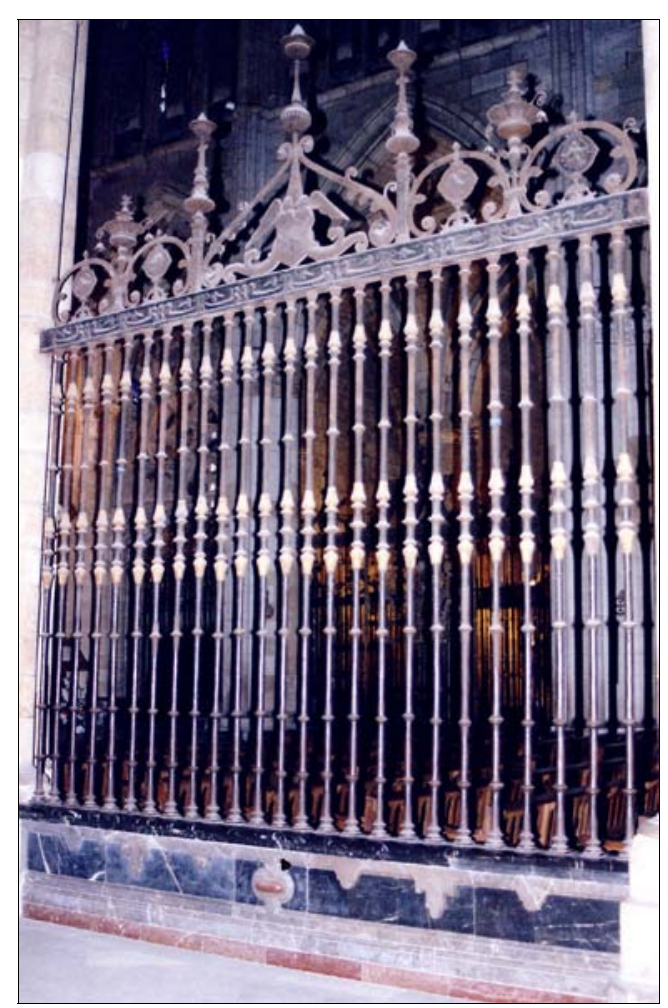

- Lám. 8. Rejas del presbiterio con el zócalo de mármoles, colocadas después del traslado del coro. (Foto del autor). 


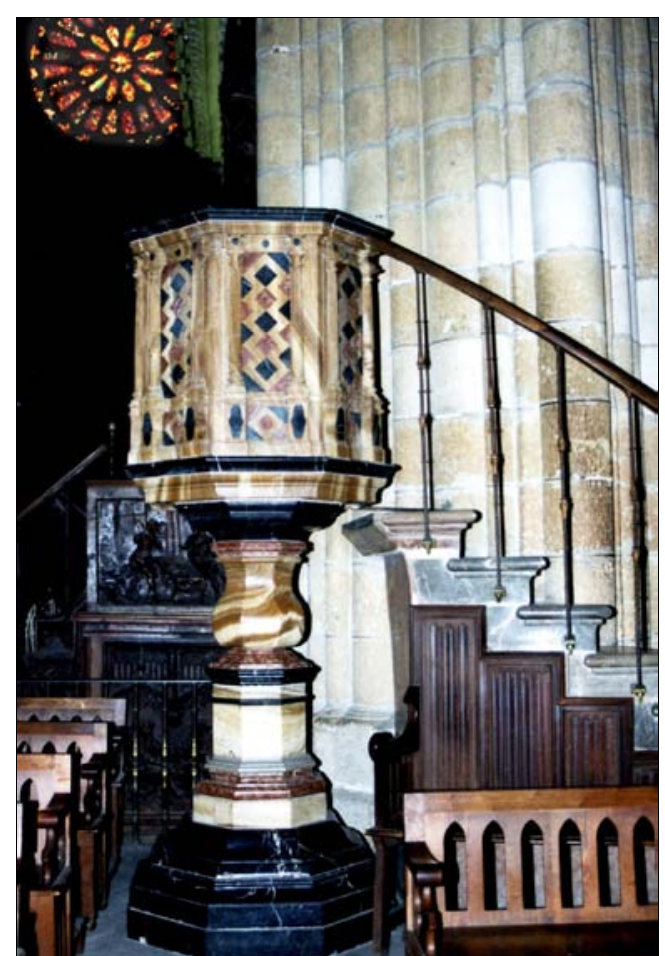

- Lám. 9. Uno de los púlpitos de la catedral situado delante del coro. (Foto del autor).

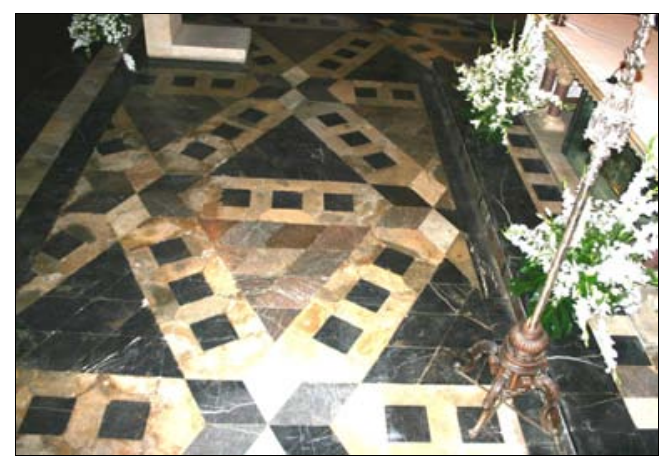

- Lám. 11. Detalle del suelo del presbiterio. (Foto del autor).

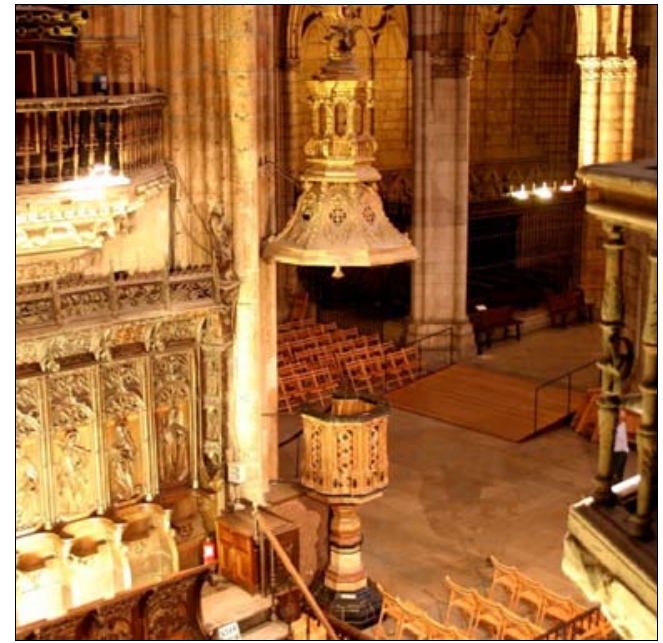

- Lám. 10. Púlpito del lado del evangelio. (Foto del autor).

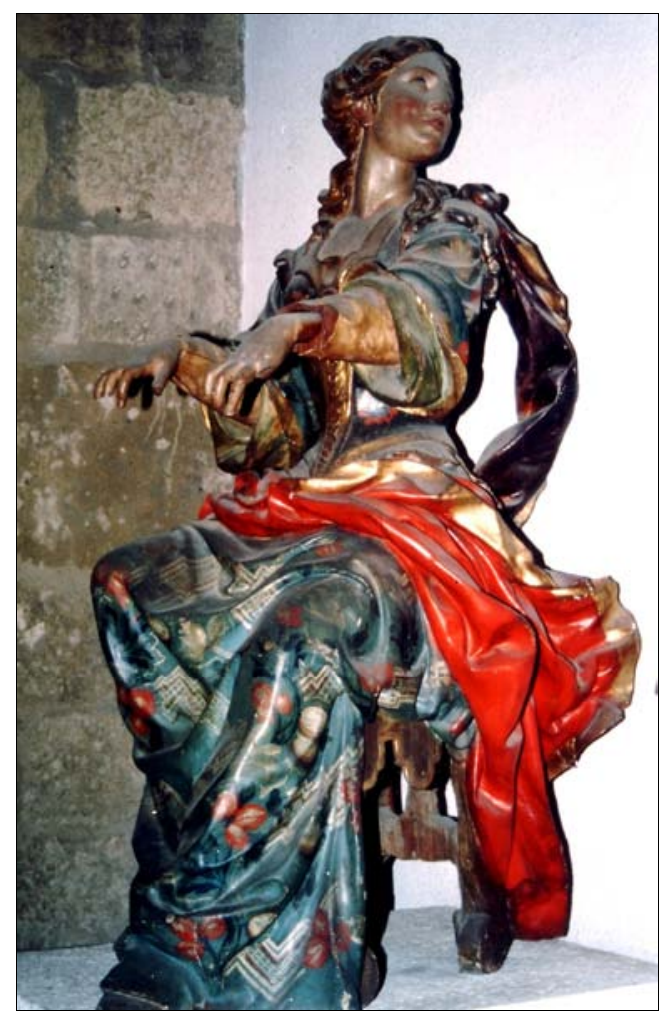

- Lám. 12. Representación de Santa Cecilia tocando el órgano. Talla de A. Carnicero. (Foto del autor). 